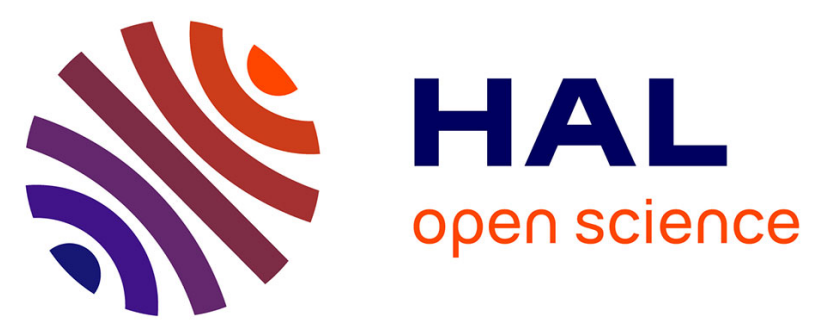

\title{
Drug-drug interaction between metformin and sorafenib alters antitumor effect in hepatocellular carcinoma cells
}

\author{
Rania Harati, Marc Vandamme, Benoit Blanchet, Christophe Bardin, \\ Françoise Praz, Rifat Akram Hamoudi, Christèle Desbois-Mouthon
}

\section{- To cite this version:}

Rania Harati, Marc Vandamme, Benoit Blanchet, Christophe Bardin, Françoise Praz, et al.. Drugdrug interaction between metformin and sorafenib alters antitumor effect in hepatocellular carcinoma cells. Molecular Pharmacology, 2021, pp.MOLPHARM-AR-2020-000223. 10.1124/molpharm.120.000223 . hal-03228343

\section{HAL Id: hal-03228343 \\ https://hal.sorbonne-universite.fr/hal-03228343}

Submitted on 18 May 2021

HAL is a multi-disciplinary open access archive for the deposit and dissemination of scientific research documents, whether they are published or not. The documents may come from teaching and research institutions in France or abroad, or from public or private research centers.
L'archive ouverte pluridisciplinaire HAL, est destinée au dépôt et à la diffusion de documents scientifiques de niveau recherche, publiés ou non, émanant des établissements d'enseignement et de recherche français ou étrangers, des laboratoires publics ou privés. 


\section{Title Page}

Drug-drug interaction between metformin and sorafenib alters antitumor effect in hepatocellular carcinoma cells

Rania Harati ${ }^{1,2}$, Marc Vandamme ${ }^{2}$, Benoit Blanchet ${ }^{3,4}$, Christophe Bardin $^{3}$, Françoise Praz $^{2,5}$, Rifat Akram Hamoudi ${ }^{6,7}$, Christèle Desbois-Mouthon ${ }^{2,8}$

1 Department of Pharmacy Practice and Pharmacotherapeutics, College of Pharmacy, University of Sharjah, Sharjah, United Arab Emirates

${ }^{2}$ Centre de Recherche Saint-Antoine, Sorbonne Université, INSERM, F-750012 Paris, France

${ }^{3}$ Département de Pharmacocinétique et Pharmacochimie, Hôpital Cochin, AP-HP, CARPEM, F-75014 Paris, France

${ }^{4}$ UMR8038 CNRS, U1268 INSERM, Faculté de Pharmacie, Université de Paris, PRES Sorbonne Paris Cité, F-75006 Paris, France

${ }^{5}$ Centre National de la Recherche Scientifique, Paris, France

${ }^{6}$ Department of Clinical Sciences, College of Medicine, University of Sharjah, Sharjah, United Arab Emirates

${ }^{7}$ Division of Surgery and Interventional Science, UCL, London, United Kingdom

${ }^{8}$ Centre de Recherche des Cordeliers, Sorbonne Université, INSERM, Université de Paris, F-75006 Paris, France 


\section{Running title Page}

a) Running title: Metformin and sorafenib in hepatocellular carcinoma

b) Corresponding author: Christèle Desbois-Mouthon, $\mathrm{PhD}$, Centre de Recherche des Cordeliers, INSERM UMR_S1138, 15 rue de l'école de médecine, 75006 Paris, France ; e-mail: christele.desbois-mouthon@inserm.fr

c) Number of pages: 44

Number of tables: 2

Number of figures: 6

Number of references: 68

Number of words in abstract: 215

Number of words in introduction: $\mathbf{5 1 1}$

Number of words in discussion: 1486

d) List of abbreviations: ADAM8: ADAM metallopeptidase domain 8; AMPK: AMP-activated protein kinase; CCL20: C-C motif chemokine ligand 20; CEACAM1: carcinoembryonic antigen-related cell adhesion molecule 1; FGF2: fibroblast growth factor 2; GPCR: G-proteins coupled receptor; HCC, hepatocellular carcinoma; IQR: interquartile range; MASH: metabolicassociated steatohepatitis; MAPK: mitogen-activated protein kinase; MTT: 3(4,5-dimethylthiazol-2-yl)-2,5-diphenyltetrazolium bromide; OATP, organic anion-transporting polypeptide; RTK, receptor tyrosine kinase; T2D: type 2 diabetes. 


\section{Abstract}

Hepatocellular carcinoma $(\mathrm{HCC})$ is the most common primary liver malignancy and is one of the leading causes of cancer-related deaths worldwide. The multi-target inhibitor sorafenib is a first-line treatment for patients with advanced unresectable HCC. Recent clinical studies have evidenced that patients treated with sorafenib together with the anti-diabetic drug metformin have a survival disadvantage compared to patients receiving sorafenib only. Here, we examined whether a clinically relevant dose of metformin $(50 \mathrm{mg} / \mathrm{kg} / \mathrm{d})$ could influence the antitumoral effects of sorafenib $(15 \mathrm{mg} / \mathrm{kg} / \mathrm{d})$ in a subcutaneous xenograft model of human HCC growth using two different sequences of administration, i.e concomitant versus sequential dosing regimens. We observed that the administration of metformin six hours prior to sorafenib was significantly less effective in inhibiting tumor growth (15.4\% tumor growth inhibition) than concomitant administration of the two drugs (59.5\% tumor growth inhibition). In vitro experiments confirmed that pretreatment of different human HCC cell lines with metformin reduced the effects of sorafenib on cell viability, proliferation and signaling. Transcriptomic analysis confirmed significant differences between xenografted tumors obtained under the concomitant and the sequential dosing regimens. Taken together, these observations call into question the benefit of parallel use of metformin and sorafenib in patients with advanced HCC and diabetes, as the interaction between the two drugs could ultimately compromise patient survival. 


\section{Significance statement}

When drugs are administrated sequentially, metformin alters the anti-tumor effect of sorafenib, the reference treatment for advanced hepatocellular carcinoma, in a preclinical murine xenograft model of liver cancer progression as well as in hepatic cancer cell lines. Defective activation of the AMPK pathway as well as major transcriptomic changes are associated with the loss of the anti-tumor effect. These results echo recent clinical work reporting a poorer prognosis for patients with liver cancer who were co-treated with metformin and sorafenib. 


\section{Introduction}

Primary liver cancer ranks at the sixth and fourth positions in terms of incidence and mortality, respectively and hepatocellular carcinoma (HCC) accounts for $90 \%$ of cases (Ferlay et al., 2019). Treatment options for HCC are limited and outcomes remain poor, especially for unresectable advanced tumors. The multi-target inhibitors sorafenib and lenvatinib have been approved as first-line treatments for patients with advanced HCC. These therapies have demonstrated significant but modest effects on overall survival (Yarchoan et al., 2019).

These last years, the etiological and epidemiological landscape of HCC has undergone significant changes. While chronic viral hepatitis $B$ and $C$ and massive alcohol consumption have been the major etiological factors for decades, the worldwide epidemic of obesity and type 2 diabetes (T2D) has revealed that these metabolic diseases are involved in the pathogenesis of $\mathrm{HCC}$, due to their ability to induce metabolic-associated steatohepatitis (MASH). MASH is becoming the leading etiology underlying many cases of $\mathrm{HCC}$, especially in industrialized countries (Anstee et al., 2019; Younossi et al., 2019).

Metformin, a widely used oral biguanide for T2D treatment, has been associated with a lower risk of HCC among diabetic patients (Cunha et al., 2020; Zhou et al., 2016) and with increased survival among HCC patients treated with surgery (Schulte et al., 2019). However, recent clinical studies have raised doubt about the efficacy of metformin and sorafenib administration in diabetic patients with advanced HCC. Indeed, it has been reported that patients treated with sorafenib had a survival disadvantage when they were treated with metformin, their overall survival being 4-5 months shorter compared to patients receiving sorafenib only (Casadei 
Gardini et al., 2017; Casadei Gardini et al., 2015; Schulte et al., 2019). Conversely, patients with HCC receiving insulin treatment showed a better response to sorafenib and longer survival (Casadei Gardini et al., 2017).

Using murine experimental models, it has been reported that the concomitant administration of metformin with sorafenib $(30 \mathrm{mg} / \mathrm{kg} / \mathrm{d})$ was more efficient than monotherapies to inhibit growth and metastatic dissemination of orthotopically engrafted MHCC97H cells (Guo et al., 2016; You et al., 2016). The metformin and sorafenib combination also led to growth inhibition of subcutaneously xenografted Bel-7402 cells compared to single agent (Ling et al., 2017). However, it is important to note that these studies were conducted with a high dose of metformin (200 $\mathrm{mg} / \mathrm{kg} / \mathrm{d}$ ), which is not consistent with the therapeutic doses achievable in diabetic patients (33-42 mg/kg/d). In addition, drugs were administrated according to a single regimen, i.e concomitant administration. Recently, Karbownik and colleagues (Karbownik et al., 2020) reported that the co-administration of metformin $(100 \mathrm{mg} / \mathrm{kg})$ and sorafenib $(100 \mathrm{mg} / \mathrm{kg})$ to rats increased the clearance of sorafenib, resulting in a lower half-life of sorafenib. This study points a potential pharmacokinetic interaction between metformin and sorafenib.

The present study was designed to examine whether a clinically relevant dose of metformin $(50 \mathrm{mg} / \mathrm{kg} / \mathrm{d})$ has antitumoral effects when administrated with sorafenib (15 $\mathrm{mg} / \mathrm{kg} / \mathrm{d}$ ) according to two different sequences, i.e. concomitant versus sequential. These experiments were conducted in a subcutaneous xenograft model of human HCC growth as well as in a panel of human HCC cell lines. 


\section{Materials and methods}

Pharmacological drugs. Sorafenib ( $p$-toluene sulfonate salt) was purchased from LC Laboratories (Woburn, MA, USA), and metformin was from Sigma-Aldrich (SaintQuentin Fallavier, France). For in vitro studies, sorafenib and metformin were dissolved in dimethylsulfoxide (Sigma-Aldrich Chemie S.a.r.l., Saint-Quentin Fallavier, France) and serum-free medium, respectively. For in vivo studies, sorafenib and metformin were dissolved in Cremophor EL/ethanol/water (12.5\%:12.5\%:75\%, Sigma-Aldrich) and sterile water, respectively. AICAR (N1-( $\beta$ DRibofuranosyl)-5-aminoimidazole-4-carboxamide) was from Tocris Bioscience (BioTechne Europe, Lille, France).

Xenografts. All in vivo experiments were approved by Charles Darwin Ethics Committee and French Ministry of Higher Education and Research under protocol number 01350.02 .

Six week-old female athymic mice (Rj:NMRI-Foxn1nu/Foxn1nu, Janvier Labs, Le Genest-Saint-Isle, France) were inoculated s.c. in the right flank with $2 \times 10^{6}$ PLC/PRF5 cells suspended in 50\% Matrigel (BD Biosciences, San Jose, CA). Mice were treated by gavage with vehicles (control), sorafenib alone $(15 \mathrm{mg} / \mathrm{kg} / \mathrm{day})$, metformin alone $(50 \mathrm{mg} / \mathrm{kg} / \mathrm{day}$ ), metformin combined to sorafenib (concomitant schedule) and metformin followed $6 \mathrm{~h}$ later by sorafenib (sequential schedule). Mice were randomly assigned to the different experimental groups. In the first set of experiments designed to evaluate the preventing effect of metformin on tumor growth, metformin $(n=7)$ and vehicle $(n=7)$ administrations were initiated four days before HCC cell grafts and maintained during the next 15 days. In the second set of 
experiments designed to evaluate the metformin/sorafenib combination, sample sizes were selected before any data had been obtained and were unequal. The control group was selected as the largest one $(n=19)$. The sizes of metformin, concomitant and sequential groups were equivalent $(n=12-14)$. The sorafenib group was chosen as the smaller one $(n=10)$ due to low variability in tumor growth response (Blivet-Van Eggelpoel et al., 2012). Tumor size was measured thrice a week using a hand caliper and tumor volume was calculated using the formula: length $\mathrm{x}$ (width $)^{2} \times 0.52$. Tumor volume measurements were not blinded, but were carried out by the same person. Mice were weighed thrice a week to follow drug toxicity. Weight loss greater than $15 \%$ was considered as a sign of toxicity. After 15 days, mice were anesthetized and tumors were excised, weighed, flash frozen in liquid nitrogen and stored at $-80^{\circ} \mathrm{C}$ for further analyses. We observed a strong correlation between tumor volumes and weights (data not shown).

Plasma concentrations of metformin and sorafenib. Plasmas were prepared from blood collected by cardiac puncture. Plasma concentrations of sorafenib were determined $2 \mathrm{~h}$ and $6 \mathrm{~h}$ post-administration by gavage using a previously described high-performance liquid chromatography method. The accuracy, within-assay and between assay precision of this method were $96.9-104.0 \%, 3.4-6.2 \%$ and $7.6-9.9 \%$, respectively (Blanchet et al., 2009). Plasma concentrations of metformin were determined $2 \mathrm{~h}$ and $4 \mathrm{~h}$ post-administration by gavage using a modified ultra highpressure liquid chromatography assay with UV DAD (diode array detector) as previously described (Bardin et al., 2012). The calibration curve for metformin was linear within the range of $0.15-20.0 \mathrm{mg} / \mathrm{L}$. Based on quality control samples, the accuracy, within-assay and between assay precision were less than $10 \%$ of the 
entire range of quantification. The accuracy of our method was ensured by our participation in the metformin proficiency testing scheme provided by the «Société Française de Toxicologie Analytique ».

Cell culture and treatments. HepG2, Hep3B, and Huh7 cells were obtained from the American Type Culture Collection (ATCC). PLC/PRF5 were provided by Dr Christine Perret (Institut Cochin, France). Cell line authentication was performed by using a panel of nine short tandem repeats as previously reported (Goumard et al., 2017). Cell lines were cultured as reported elsewhere (Blivet-Van Eggelpoel et al., 2012) and routinely controlled for mycoplasma contamination. Human hepatocytes in primary culture were obtained as reported elsewhere (Aoudjehane et al., 2016).

Cell viability and proliferation. Cell viability was evaluated using the 3-(4,5dimethylthiazol-2-yl)-2,5-diphenyltetrazolium bromide assay (MTT assay) as previously reported (Desbois-Mouthon et al., 2009). Cell proliferation was evaluated by direct cell counting and by staining DNA with $0.1 \%$ crystal violet in $20 \%$ methanol during $30 \mathrm{~min}$ at room temperature with gentle shaking. Crystal violet dye was extracted using $10 \% \mathrm{SDS}, 0.01 \mathrm{mM} \mathrm{HCl}$ at $37^{\circ} \mathrm{C}$ during $1 \mathrm{~h}$ and absorbance was determined at $570 \mathrm{~nm}$ in a microplate reader (Infinite F200 PRO, Tecan, Switzerland).

Western blotting. Protein electrophoresis and transfer to nitrocellulose were performed according to standard procedures and primary antibodies against phospho-AMPK $\alpha$ (Thr172) (40H9), and AMPK $\alpha$ (Cell Signaling Technology Europe, 
Leiden, Netherlands) were used. Blot revelations were performed using ChemiDocTM Touch Imaging System (BIO-RAD, Hercules, CA, USA).

RNA isolation and analysis of gene expression. Total RNA was extracted from cell cultures using Nucleospin RNA kit (Macherey-Nagel SARL, Hoerdt, France). Quantitative measurements of transcripts were performed by real-time PCR on a LightCycler 96 instrument (Roche Diagnostics, Meylan, France) using SYBR Green chemistry and specific primers for $A B C B 1$ (coding for MDR1/PgP) (forward: 5'GAAATTTAGAAGATCTGATGTCAAACA-3', reverse: 5'ACTGTAATAATAGGCATACCTGGTCA-3'), ABCG2 (coding for BCRP) (forward: 5'TGGCTTAGACTCAAGCACAGC-3', reverse: 5'-TCGTCCCTGCTTAGACATCC-3'), RALBP1 (coding for RLIP76) (forward: 5'-CGGCTCTCTCGCTGTACATT-3', reverse: 5'-GAACCTGAGCCTGACGTGAA-3'), SLC22A1 (coding for OCT1) (forward: 5'CTGAGGGAGACATTGCACCT-3', reverse: 5'-TGCTCCAGAATGTCATCCAC-3'), SLCO1B1 (coding for OATP1B1) (forward: 5'-GGGTGGACTTGTTGCAGTTG-3', reverse: 5'-TGTTTTTGTTGTTGATGCTCAGT-3'), and SLCO1B3 (coding for OATP1B3) (forward: 5'-TCAAGTGGTATTAAAAAGCATACAGTG-3', reverse: 5'TTCACCCAAGTGTGCTGAGT-3'). For each sample, gene expression was normalized to that of hypoxanthine guanine phosphoribosyltransferase mRNA content (forward: 5'-TAATTGGTGGAGATGATCT-3', reverse: 5'TGCCTGACCAAGGAAAGC-3'). HPRT mRNA was used to standardize RT-qPCR experiments because this transcript is one of the most stable house-keeping mRNAs between the different $\mathrm{HCC}$ cell lines and its $\mathrm{Cq}$ values were close to those of the genes of interest. In addition, the expression of HPRT mRNA was not altered after 
metformin treatment in HCC cell lines (data not shown). The relative quantity of each target gene was determined from replicate samples using the formula $2^{-\Delta \Delta C t}$.

Uptake of radiolabeled sorafenib. HCC cells $\left(7 \times 10^{4}\right.$ cells/well) grown in 24-well plates were preincubated for 30 minutes at $37^{\circ} \mathrm{C}$ in uptake buffer $(96 \mathrm{mM} \mathrm{NaCl}, 5.3$ $\mathrm{mM} \mathrm{KCl}, 1.1 \mathrm{mM} \mathrm{KH} 2 \mathrm{PO}_{4}, 0.8 \mathrm{mM} \mathrm{MgSO}_{4}, 1.8 \mathrm{mM} \mathrm{CaCl}_{2}, 11 \mathrm{mM}$ D-glucose, $50 \mathrm{mM}$ HEPES, pH 7.4). Experiments were initiated by replacement of uptake medium with $0.5 \mathrm{ml}$ of $0.2 \mu \mathrm{Ci} / \mathrm{mL}\left[{ }^{3} \mathrm{H}\right]$ sorafenib $(0.1-3 \mathrm{Ci}(3.7-111 \mathrm{GBq}) / \mathrm{mmol}$, Moravek Inc., Brea, CA, USA) in uptake buffer. Initially, time-dependent experiments were conducted for up to 20 minutes to determine the linear uptake range (unpublished data). After incubation, radioactive solutions were aspirated and cells were washed four times with $4^{\circ} \mathrm{C}$ uptake buffer. Cells were lysed with $500 \mu \mathrm{L}$ of $0.1 \mathrm{~N} \mathrm{NaOH} / 0.1 \%$ SDS for 4 hours, and samples were analyzed by liquid scintillation counting. Data were normalized to protein concentration determined using BCA protein assay reagent kit.

Gene expression microarray. Total RNA was extracted using Trizol (ThermoFischer Scientific) from tumors collected from mice xenografted and treated with vehicle (control), metformin (50 mg/kg/day) combined to sorafenib (15 $\mathrm{mg} / \mathrm{kg} / \mathrm{day}$ ) (concomitant schedule) or metformin (50 mg/kg/day) followed 6 hours later by sorafenib (15 mg/kg/day) (sequential schedule). RNA integrity was assessed using the Agilent 2100 Bioanalyzer (Agilent Technologies, Palo Alto, CA, USA). Total RNA was amplified and labelled using the GeneChip ${ }^{T M}$ WT PLUS Reagent Kit (ThermoFischer Scientific). Each RNA sample was hybridized to Human Clariom ${ }^{\mathrm{TM}} \mathrm{S}$ GeneChip (ThermoFischer Scientific). Arrays were scanned, and images were analyzed and controlled for hybridization artefacts. 
Microarray analysis. The microarray data were normalized using Signal Space Transformation-RMA (SST-RMA) which is optimized for under-estimation of true fold changes (Irizarry et al., 2003). Following normalization, differential expression was carried out using eBayes function and one-way ANOVA statistical analysis. The analysis was carried out using Transcriptome Analysis Console software (ThermoFischer Scientific, version 4.0.2) with $p<0.05$ considered as statistically significant. The differentially expressed genes were then subjected to absolute GSEA searching through more than 10,000 different cellular pathways as described in Hamoudi et al. (Hamoudi et al., 2010). C2 is an MSigDB (The Molecular Signature Database) collection consisting of sets curated from biomedical literature and online pathway databases such as the Kyoto Encyclopedia of Genes and Genome (KEGG) (Kanehisa and Goto, 2000) or Reactome (Croft et al., 2011). The gene ontology set C5 contains curated sets derived from Gene Ontology (Ashburner et al., 2000). The data discussed in this publication have been deposited in NCBl's Gene Expression Omnibus and are accessible through GEO series accession number GSE162557.

Statistical Analysis. The experiments performed in this study were exploratory in nature and designed to evaluate the antitumoral effects of metformin in combination with sorafenib according to two different regimens. The current study did not employ a predefined study design; as such, reported $P$ values are descriptive. Statistical analyses were performed using GraphPad Prism software (San Diego, USA). When a parametric distribution was assumed, data are provided as mean \pm SD and statistically analyzed with one-way ANOVA (post-hoc Tukey's test). When a nonparametric distribution was assumed, data are presented as median (IQR) and 
statistically analyzed with Kruskal-Wallis test (post-hoc Dunn's test). Differences were considered statistically significant at $p<0.05$. 


\section{Results}

\section{In vivo effects of a clinically-relevant dose of metformin in combination with}

sorafenib on HCC growth

A low dose of metformin $(50 \mathrm{mg} / \mathrm{kg} / \mathrm{d})$ was administrated by gavage in the following experiments. This dose which is comparable with that used in metformin-treated diabetic patients $(33.3-42.5 \mathrm{mg} / \mathrm{kg} / \mathrm{d})$, has been reported to reduce insulin resistance and to normalize blood glucose levels in diabetic mice but had no effect on glycemia in control mice (Foretz et al., 2010; Heishi et al., 2006; Hou et al., 2010). We confirmed that the intra-gastric administration of $50 \mathrm{mg} / \mathrm{kg} / \mathrm{d}$ metformin to nude mice led to median (IQR) plasma metformin concentrations that reached $0.56(0.36-0.73)$ $\mathrm{mg} / \mathrm{L}$ two hours after administration (Table 1), which was close to the therapeutic values observed in humans (Lalau et al., 2011).

The first set of experiments was designed to evaluate the effect of the low dose of metformin alone on tumor growth in a model of subcutaneously xenografted PLC/PRF5 cells. Metformin and vehicle administrations were initiated four days before $\mathrm{HCC}$ cell grafts and maintained during the next 15 days. We observed that 50 $\mathrm{mg} / \mathrm{kg} / \mathrm{d}$ metformin altered neither tumor initiation (100\% of mice developed tumors), nor the kinetics of tumor growth in comparison with the control group (Figure 1a,b).

In the second set of experiments, the ability of $50 \mathrm{mg} / \mathrm{kg} / \mathrm{d}$ metformin to improve the antitumoral effect of sorafenib was evaluated on established xenografted tumors $\left(\sim 250 \mathrm{~mm}^{3}\right)$. A dose of $15 \mathrm{mg} / \mathrm{kg} / \mathrm{d}$ sorafenib was used in these experiments, which is equivalent to that used in humans for the treatment of advanced HCC (800 $\mathrm{mg} / \mathrm{d}$ ). This dose led to median (IQR) plasma sorafenib concentrations of 2.98 (1.343.23) $\mathrm{mg} / \mathrm{L}$ two hours post administration in nude mice (Table 1) (therapeutic 
concentrations in humans: $2-5 \mathrm{mg} / \mathrm{L})$. In order to define the optimal sequence, two administration schedules were followed: metformin was administrated concomitantly to sorafenib (concomitant schedule) or 6 hours before sorafenib (sequential schedule). In mice, the plasma half-life of metformin is relatively short (1-2 h) and metformin concentrations in xenografted tumors have also been reported to decrease rapidly (Cai et al., 2019; Dowling et al., 2016). Thus, we chose a 6-hour interval between the two drugs to administer sorafenib when intra-tumoral concentrations of metformin were supposed to be low. Groups of mice receiving vehicle, sorafenib or metformin alone were run in parallel. Of note, four mice in the concomitant group showed signs of tumor necrosis in the course of the experiment which led to sacrifice and exclude them from analysis. As shown on Figure 1c,d and Table 2, $15 \mathrm{mg} / \mathrm{kg} / \mathrm{d}$ sorafenib alone significantly reduced by $42.3 \%$ tumor volume as compared to the control group. When metformin and sorafenib were administrated concomitantly, tumor volumes were significantly reduced and tended to be smaller than those obtained with sorafenib alone (59.5\% tumor growth inhibition as compared to the control group). In contrast, the sequential therapy had no significant antitumor effect (15.4\% tumor growth inhibition as compared to the control group). The analysis of tumor weights at sacrifice confirmed that the sequential schedule was not effective to reduce tumor weight (Figure 1e). None of the different treatments showed toxicity as monitored by body weight evaluation (data not shown). Altogether, these data indicate that metformin has schedule-dependent antitumor effects against HCC cells when combined with sorafenib; the sequential schedule (administration of metformin $6 \mathrm{~h}$ before sorafenib) seems to impair the anticancer activity of sorafenib. 


\section{Effects of metformin on plasma concentrations of sorafenib}

To approach the potential mechanisms accounting for metformin-mediated inhibition of sorafenib effect, we first measured plasma concentrations of sorafenib. The maximal plasmatic concentrations of sorafenib in mice have been previously reported between 1.5 and 2 hours after oral administration (EMA, 2007; Edginton et al., 2016). Therefore, sampling points performed 2 and 6 hours after sorafenib administration were chosen to characterize the absorption and elimination phases of sorafenib pharmacokinetics, respectively. Plasma concentrations were measured in mice treated with sorafenib alone, sorafenib and metformin concomitantly during $2 \mathrm{~h}$ or $6 \mathrm{~h}$ as well as in mice pretreated with metformin during $2 \mathrm{~h}$ or $4 \mathrm{~h}$ and then exposed to sorafenib during $2 \mathrm{~h}$. As shown in Table 1, the concomitant and sequential administrations of metformin did not modify the plasmatic concentrations of sorafenib as compared to those obtained in mice treated with sorafenib alone.

\section{In vitro effects of metformin in combination with sorafenib on HCC cell viability and proliferation}

We then analyzed the effects of metformin and sorafenib on the viability of the PLC/PRF5 cell line using an in vitro MTT assay. As shown in Figures $\mathbf{2 a}$ and $\mathbf{2 b}$, the concomitant treatment of PLC/PRF5 cells with suboptimal concentrations of metformin and sorafenib decreased cell viability to a larger extent than did each drug alone. In contrast, the sequential treatment (pre-treatment with metformin during $6 \mathrm{~h}$ ) was significantly less effective to reduce cellular viability than the concomitant treatment. We extended analyses to three human other liver cancer cell lines, namely Hep3B, HepG2 and Huh7. In these three cell lines, the concomitant combination of 
metformin with sorafenib was significantly more efficient to reduce cell viability than was the sequential schedule (Figure 2a).

As metformin is known to affect the mitochondrial complex 1 of the respiratory chain, it might interfere with the MTT assay, which relies on mitochondrial activity. Therefore, we also evaluated the effects of concomitant and sequential treatments on HCC cell proliferation using two assays that do not rely on cell functionalities. As shown in Figures $\mathbf{3 a}$ and $\mathbf{3} \mathbf{b}$, the concomitant treatment was more potent than the sequential schedule to reduce proliferation in PLC/PRF5 and Huh7 cells evaluated both by cell counting and DNA staining with crystal violet. Altogether, these data support the conclusion that when metformin was administrated before, the antiproliferative effect of sorafenib was reduced in vitro.

\section{Effects of metformin on sorafenib uptake in HCC cells}

We then investigated whether metformin may alter sorafenib uptake in HCC cells. Sorafenib uptake has been reported to occur via both passive (Hu et al., 2009; Swift et al., 2013) and active (Herraez et al., 2013; Swift et al., 2013; Zimmerman et al., 2013) diffusion in different cell types. The active portion may involve organic aniontransporting polypeptides (OATPs) 1B1 and 1B3 and organic cation transporter-1 (OCT1). As shown in Figure $\mathbf{4 a}$, hepatic cancer cell lines exhibited low levels of OATP1B1, OATP1B3 and OCT1 transcripts compared to normal human hepatocytes. Cell treatment with metformin $(1 \mathrm{mM}, 24 \mathrm{~h})$ had no effect on mRNA expression of influx transporters (data not shown).

Efflux clearance of sorafenib has been shown to be mediated by different transporters. BCRP/ABCG2 functions as an efflux pump for sorafenib in vivo in mouse brain (Agarwal and Elmquist, 2012; Agarwal et al., 2011; Tang et al., 2013) 
and in vitro in MDCKII and Hep3B cells (Huang et al., 2013; Poller et al., 2011). RLIP76, a stress-responsive membrane protein, has been identified as a transporter for sorafenib in kidney cancer cells (Singhal et al., 2010). In contrast, sorafenib seems to be a weak substrate for Pgp/MDR1/ABCB1 in vitro in the K562/Dox cell line (Haouala et al., 2010) and in vivo in mouse (Agarwal and Elmquist, 2012). These three pumps were expressed differentially in HCC cell lines (Figure $\mathbf{4 b}$ ) and cell treatment with metformin $(1 \mathrm{mM}, 24 \mathrm{~h})$ was without any effect on mRNA expression of efflux transporters (data not shown).

We examined whether cell pretreatment with metformin may impact drug uptake using radiolabeled $\left[{ }^{3} \mathrm{H}\right]$ sorafenib. Experiments were performed at $37^{\circ} \mathrm{C}$ and also at $4^{\circ} \mathrm{C}$ to assess the contribution of passive diffusion to overall uptake. The uptake of $\left[{ }^{3} \mathrm{H}\right]$ sorafenib at $4^{\circ} \mathrm{C}$ was reduced by $58 \%$ compared with $37^{\circ} \mathrm{C}$ confirming a substantial degree of passive diffusion (Figure 4c). At both temperatures, cell pretreatment with metformin during six hours did not alter sorafenib cellular accumulation (Figure 4c, d). These data did not support for a role of metformin on the regulation of sorafenib disposal into HCC cells in vitro.

\section{In vitro effects of metformin in combination with sorafenib on AMPK phosphorylation}

The combination of metformin and sorafenib has been reported to be synergistic in non-small cell lung cancer cells through AMP-activated protein kinase (AMPK) activation (Groenendijk et al., 2015). Therefore, we next investigated whether sequential and concomitant regimens differentially affected the AMPK pathway. Using AICAR which is a cell permeable activator of AMPK (through its phosphorylation) in different cancer cell lines including HCC cells (Cheng et al., 
2014), we observed that the concomitant treatment of PLC/PRF5 and Huh7 cells with AICAR and sorafenib reduced cell viability more efficiently than drugs alone while the sequential treatment turned to be less potent (Figure 5a). These data mimic those obtained with the metformin/sorafenib combinations (Figure 2) and suggest that the cross-resistance observed between metformin and sorafenib in the sequential schedule may be associated with an inadequate stimulation of AMPK activity. To test this hypothesis, the phosphorylation level of AMPK was examined by Western blot analysis in the different cell lines treated during $24 \mathrm{~h}$ with drugs alone, drugs in combination or with metformin during $6 \mathrm{~h}$ followed by sorafenib for the next $18 \mathrm{~h}$. As shown in Figure 5b, the concomitant treatment increased the activation level of AMPK in comparison with control while the sequential treatment led to a lower activation of AMPK in the four HCC cell lines.

\section{Genes differentially expressed in concomitant and sequential regimens}

To better characterize the molecular signatures driving the differential responses to concomitant and sequential bitherapies, we conducted a transcriptomic analysis on RNA extracted from tumor xenografts. Using Anova to filter differentially expressed genes obtained from eBayes function, 1035 genes were identified to be differentially expressed between control and concomitant treatments, 771 genes between control and sequential treatments and 1051 between sequential and concomitant treatments. Among these differentially expressed genes, 193 were commonly altered by both types of treatments (sequential and concomitant) while 842 genes were altered by the concomitant treatment only and 578 genes by the sequential treatment (Figure $6 \mathbf{a}, \mathbf{b})$. 
The differentially expressed genes were subjected to absolute GSEA searching through more than 10,000 different cellular pathways (Figure 6b). The analysis identified 6 and 24 pathways derived from the C2 and C5 gene sets respectively as differentially expressed between the control and concomitant treatments, while 15 and 18 pathways derived from the C2 and C5 gene sets respectively were differentially expressed between the control and sequential treatments (Tables S2 and S3). Ten pathways derived from C2 gene sets and 5 pathways from C5 gene sets were differentially expressed between concomitant and sequential treatments (Table S4).

Some of the pathways identified for the concomitant treatment are related to Gproteins coupled receptors (GPCR) and transmembrane receptors signaling such as GO_G_PROTEIN_COUPLED_RECEPTOR_ACTIVITY (GO:0007186) and GO_TRANSMEMBRANE_SIGNALING_RECEPTOR_ACTIVITY (GO:0004888). Some of the pathways identified for the sequential treatment are related to protein kinases, receptor tyrosine kinases (RTKs) and mitogen-activated protein kinase (MAPK) signaling such as REACTOME SIGNALING BY RECEPTOR TYROSINE KINASES (R-HSA-9006934), POSITIVE REGULATION OF MAPK CASCADE (GO:0043410) and GO_REGULATION_OF_PHOSPHORUS_METABOLIC_PROCESS (GO:0051174). Some of the pathways differentially expressed between sequential and concomitant treatments are also related to GPRC such as REACTOME_SIGNALING_BY_GPCR (R-HSA-372790), REACTOME_GPCR_LIGAND_BINDING (R-HSA-500792), GO_G_PROTEIN_COUPLED_RECEPTOR_ACTIVITY (GO:0004930) as well as cell proliferation such as BENPORATH_EED_TARGETS (M7617) (Figure 6c). 
For each significant pathway, the enriched genes were identified and their recurrence in other pathways was searched as previously described (Hamoudi et al., 2010). The genes detected in more than three different pathways were considered of significance for the drug mechanism of action (Table S5). Applying this approach to concomitant drug treatment, 11 members of the olfactory receptors family (such as OR1OH3 and OR7G1) as well as other genes such as CEACAM1, SCN1A, and $A D A M 8$ amongst others were found significantly overexpressed in treated tumors compared to untreated control tumors $(\mathrm{OR} 1 \mathrm{OH} 3$ : fold change $=1.38, p=0.0228$; OR11G2 $:$ fold change $=1.29, p=0.0175 ;$ OR13D1: fold change $=1.33, p=0.0347 ;$ CEACAM1: fold change $=2.84, p=0.0009 ;$ ADAM8: fold change $=1.65, p=0.017$ ) while 7 members of the olfactory receptors family (such as OR2AG2 and OR2T10) were down-regulated (OR2AG2: fold change $=-1.43, p=0.0173 ;$ OR2T10: fold change $=-1.35, p=0.0137)$.

In sequential treatment, PRKAR1A, STAT3, STAT5B, IRS2, AKT2 and CEACAM1 were overexpressed in treated tumors $(P R K A R 1 A$ : fold change $=1.68, p$ $=0.0254 ;$ STAT3: fold change $=1.18, p=0.03 ;$ STAT5B: fold change $=1.33, p=$ $0.0135 ;$ IRS2: fold change $=2.01, p=0.0212 ;$ AKT2: fold change $=1.42, p=0.0163 ;$ CEACAM1: fold change $=1.71, p=0.0304$ ) while FGF2 and CCL20 were downregulated amongst others (FGF2: fold change $=-1.55, p=0.02 ;$ CCL20: fold change $=-1.91, p=0.002$ )

Comparing the two modes of treatments, genes detected in more than three pathways and upregulated in sequential treatment compared to concomitant one include PDE4DIP (fold change $=1.91, p=0.0245$ ), while downregulated genes include PYY (fold change $=-1.55, p=0.0036$ ) and WNT1 (fold change $=-1.24, p=$ 0.0389). 
Altogether these data substantiate the notion that the combination of metformin and sorafenib according to sequential and concomitant regimens leads to qualitatively and quantitatively different signaling pathways in HCC tumors that may account for differential antitumor responses. 


\section{Discussion}

In the present study, we investigated the underlying mechanisms that may account for the clinical finding that patients receiving both metformin and sorafenib have reduced survival compared to to patients receiving sorafenib alone (Casadei Gardini et al., 2017; Casadei Gardini et al., 2015; Schulte et al., 2019). Using a xenograft model of HCC growth, we identified a differential therapeutic response to the bitherapy metformin/sorafenib depending upon the drug administration schedule (concomitant versus sequential) and provide novel insights into the complex and interactive molecular mechanism of the metformin/sorafenib combination.

Sorafenib is the gold standard, first-line systemic treatment for advanced HCC since 2007. It provides a modest but significant survival benefit over placebo (Marisi et al., 2018). Sorafenib is a multi-kinase inhibitor targeting Raf kinase activity, STAT3-dependent signaling and RTKs such as vascular endothelial growth factor receptor, platelet-derived growth factor receptor- $\beta$ and c-KIT (Tai et al., 2011; Wilhelm et al., 2008). These pleiotropic actions confer to sorafenib potential inhibitory effects on tumor cell proliferation and neovascularization.

Because of its great potency to reduce liver glucose production, its relatively low cost and its safety profile even in case of cirrhosis (Bhat et al., 2014; Zhang et al., 2014), metformin is the first medication prescribed to patients with T2D. Several studies have also reported a preventive role of metformin on HCC development among diabetic patients (Cunha et al., 2020; Zhou et al., 2016). This is thought to be related to the glucose-lowering and insulin-sensitizing effects of metformin which might reduce the proliferation rate of premalignant hepatic lesions that thrive in high-glucose and/or high-insulin environment. In addition, direct antitumor effects of metformin have 
been reported in vitro in HCC cells (Hu et al., 2019; Miyoshi et al., 2014; Tsai et al., 2017).

Recent observational clinical studies have cast doubt on the benefits for patients with HCC and diabetes to be treated simultaneously with sorafenib and metformin. Indeed, it has been reported that the use of sorafenib and metformin in patients with advanced HCC was associated with a poorer prognosis compared to the use of sorafenib alone (Casadei Gardini et al., 2017; Casadei Gardini et al., 2015; Schulte et al., 2019). These results were rather unexpected as preclinical experimental data were encouraging showing that the concomitant administration of metformin to sorafenib was more efficient than drugs alone to inhibit HCC tumor growth as well metastatic dissemination in immunodeficient mice bearing xenografts of human HCC cells (Guo et al., 2016; Ling et al., 2017; You et al., 2016). However, one limitation of these studies is that metformin was used at a high concentration (>200 mg/kg/d) generally unachievable in diabetic patients.

Therefore, we conducted the present study to re-evaluate the antitumor potential of the combination metformin/sorafenib, taking into account not only the dose of metformin used but also the drug administration regimen. In contrast to the results reported with high doses of metformin (Cauchy et al., 2017; Chen et al., 2013; Saito et al., 2013; Zheng et al., 2013), we observed that a low dose of metformin $(50 \mathrm{mg} / \mathrm{kg} / \mathrm{d})$ was unable to inhibit the growth of established tumors in a HCC xenograft model. In this model, the co-administration of sorafenib with a low dose of metformin induced a significant reduction in tumor volume and weight compared to control but was not significantly more effective than sorafenib monotherapy. Taken together, these data suggest that the antitumor effect of metformin cannot be achieved in vivo at a clinically-relevant dose. 
Intriguingly, the sequential administration of metformin $6 \mathrm{~h}$ prior to sorafenib significantly impaired the anti-cancer effect of sorafenib on tumor growth in the HCC xenograft model. These observations were reproduced in vitro using a panel of four human $\mathrm{HCC}$ cell lines known to be genetically and phenotypically different (Caruso et al., 2019), which supports the relevance of our findings. Cell pretreatment with metformin impaired sorafenib effects on $\mathrm{HCC}$ cell viability and proliferation in vitro. Interestingly, we performed preliminary experiments with sunitinib which is also a pan-inhibitor of receptor tyrosine kinases. In a similar way to what was observed with sorafenib, we found that the sequential treatment with metformin was less effective than the concomitant treatment to decrease cell viability in the PLC/PRF5 cell line (Supplementary Fig. S1) suggesting that metformin may more generally interfere with this class of anti-cancer drugs.

Prior administration of metformin impacted neither the plasma concentrations of sorafenib 2 and $6 \mathrm{~h}$ after its administration, nor the intracellular bioavailability of sorafenib in HCC cells in vitro. Karbownik et al. (Karbownik et al., 2020) recently showed that the concomitant administration of metformin $(100 \mathrm{mg} / \mathrm{kg})$ increases the clearance of sorafenib $(100 \mathrm{mg} / \mathrm{kg})$ in rats, which results in a lower sorafenib half-life (16.3 \pm 3.7 vs $21.9 \pm 7.8 \mathrm{~h}, p=0.0372)$. This result was obtained from complete sorafenib pharmacokinetics including sampling points up to $96 \mathrm{~h}$. The difference was particularly significant during the terminal elimination phase (i.e. $24 \mathrm{~h}$ after the administration). Therefore, our limited sampling strategy (two sampling points at 2 and $6 \mathrm{~h}$ after administration) is a limiting factor to draw any conclusion about the pharmacokinetic interaction between metformin and sorafenib and this point deserves further characterization. According to the results of Karbownik et al. (Karbownik et al., 2020), we should have expected a lower total exposure to 
sorafenib in our murine model cotreated with metformin. However, coadministration of sorafenib plus metformin was associated with a greater decrease in tumor volume compared to sequential therapy in our model, which suggests that the differential effects between the two regimens may be the result of pharmacodynamic rather than pharmacokinetic interactions.

The sequential use of metformin and sorafenib led to a poorer activation of AMPK in HCC cell lines than did the concomitant treatment. Metformin alone has been reported to exert some of its anti-cancer effects in HCC cells through the activation of AMPK and the subsequent inhibition of mTOR signaling (Cheng et al., 2014; Zheng et al., 2013). In addition, low levels of AMPK signaling has been associated with HCC cell resistance to sorafenib (Bort et al., 2019). Together with our in vitro findings showing that cell pre-treatment with AICAR, another AMPK activator, impaired $\mathrm{HCC}$ cell response to sorafenib, these data sustain the hypothesis that the deficit in AMPK signaling as evidenced in HCC cells pre-treated with metformin participates to tumor cell resistance to sorafenib.

The microarray analysis performed on RNA extracted from tumor xenografts confirmed that gene expression and cellular pathways are differentially altered by sequential and concomitant treatments with metformin and sorafenib. Of interest, pathways altered by the concomitant treatment mainly involve GPCRs that may account for its beneficial effect observed in vivo compared to sequential. GPCRs are known to increase intracellular levels of cAMP by activating adenylate cyclase which may concur to the subsequent stimulation of PKA, LKB1 and AMPK. In contrast, the sequential regimen rather altered pathways involving RTKs (IRS2 and AKT2 overexpression), STAT signaling (STAT3 and STAT5B overexpression) and perturbation of cAMP signaling (PRKAR1A) that may account for its lack of efficacy 
compared to the concomitant administration. PRKAR1A codes for the type $1 \square$ regulatory subunit of PKA and its overexpression has been reported in different cancer cell types. Downregulation of PRKAR1A in cancer cells with siRNA was shown to activate PKA through release of the catalytic subunit from the holoenzyme (Nadella et al., 2008).

The transcriptomic analysis also showed that both regimens induce expression of genes associated with therapeutic resistance and tumor progression. Regarding the sequential treatment, microarray analysis identified FGF2 (fibroblast growth factor 2) and CCL2O (C-C motif chemokine ligand 20) as downregulated after sequential treatment. FGF2 downregulation could reduce elimination of $\mathrm{HCC}$ cells by natural killer-mediated innate immunity as previously reported (Tsunematsu et al., 2012) and thus contributing to reduce treatment efficacy. As upregulation of CCL2O was previously reported in sorafenib responders versus non responders (Covell, 2017), its downregulation is probably a marker of inefficacy of sequential combination. CEACAM1 (carcinoembryonic antigen-related cell adhesion molecule 1) was upregulated in combinatory and sequential treatments and its upregulation has been associated with $\mathrm{HCC}$ invasion, progression and recurrence (Kiriyama et al., 2014; Park et al., 2020; Yoshikawa et al., 2017). ADAM8 (ADAM metallopeptidase domain 8) was overexpressed in concomitant treatment versus control. High expression of $A D A M 8$ was previously found to correlate with progression and poor prognosis in patients with HCC (Jiang et al., 2012; Zhang et al., 2013). These data suggest that despite its ability to target GPCR and AMPK signaling, the combination metformin/sorafenib may also induce adverse signaling pathways that ultimately contribute to drug resistance and treatment failure, raising doubt about its benefit in the treatment of HCC. 
In conclusion, our study provides important information on the molecular mechanisms of action of the metformin/sorafenib combination and suggests a pharmacodynamics drug interaction between the two molecules leading to a loss of antitumor activity. Our data call into question the benefit of parallel use of the two drugs in patients suffering from both advanced $\mathrm{HCC}$ and diabetes as this interaction could ultimately compromise patient survival. 


\section{Acknowledgements}

The authors are greatly indebted to Corina Buta and Alkaly Gassama for their technical assistance. We thank Sébastien Jacques, Angéline Duché and Franck Letourneur from the platform GENOM'IC (Cochin Institute, INSERM U1016, Paris) for microarray experiments, Tatiana Ledent and the staff of the animal facility of the Saint-Antoine Research Center (INSERM UMR_S938) for animal care and welfare. 
10. Authorship contributions

Participated in Research design: Harati, Vandamme, Desbois-Mouthon

Conducted experiments: Harati, Vandamme, Desbois-Mouthon

Contributed new reagents or analytic tools: Blanchet, Bardin, Hamoudi

Performed data analysis: Harati, Vandamme, Hamoudi, Desbois-Mouthon

Wrote or contributed to the writing of manuscript: Harati, Blanchet, Praz, Hamoudi, Desbois-Mouthon 


\section{References}

Agarwal S and Elmquist WF (2012) Insight into the cooperation of P-glycoprotein $(A B C B 1)$ and breast cancer resistance protein (ABCG2) at the blood-brain barrier: a case study examining sorafenib efflux clearance. Molecular pharmaceutics 9(3): 678-684.

Agarwal S, Sane R, Ohlfest JR and Elmquist WF (2011) The role of the breast cancer resistance protein $(A B C G 2)$ in the distribution of sorafenib to the brain. The Journal of pharmacology and experimental therapeutics 336(1): 223-233.

Anstee QM, Reeves HL, Kotsiliti E, Govaere O and Heikenwalder M (2019) From NASH to HCC: current concepts and future challenges. Nature reviews Gastroenterology \& hepatology 16(7): 411-428.

Aoudjehane L, Boelle PY, Bisch G, Delelo R, Paye F, Scatton O, Housset C, Becquart J, Calmus $Y$ and Conti F (2016) Development of an in vitro model to test antifibrotic drugs on primary human liver myofibroblasts. Lab Invest 96(6): 672-679.

Ashburner M, Ball CA, Blake JA, Botstein D, Butler H, Cherry JM, Davis AP, Dolinski K, Dwight SS, Eppig JT, Harris MA, Hill DP, Issel-Tarver L, Kasarskis A, Lewis S, Matese JC, Richardson JE, Ringwald M, Rubin GM and Sherlock G (2000) Gene ontology: tool for the unification of biology. The Gene Ontology Consortium. Nat Genet 25(1): 25-29.

Bardin C, Nobecourt E, Larger E, Chast F, Treluyer JM and Urien S (2012) Population pharmacokinetics of metformin in obese and non-obese patients with type 2 diabetes mellitus. Eur J Clin Pharmacol 68(6): 961-968.

Bhat M, Chaiteerakij R, Harmsen WS, Schleck CD, Yang JD, Giama NH, Therneau TM, Gores GJ and Roberts LR (2014) Metformin does not improve survival in patients with hepatocellular carcinoma. World J Gastroenterol 20(42): 15750-15755.

Blanchet B, Billemont B, Cramard J, Benichou AS, Chhun S, Harcouet L, Ropert S, Dauphin A, Goldwasser F and Tod M (2009) Validation of an HPLC-UV method for sorafenib determination in human plasma and application to cancer patients in routine clinical practice. J Pharm Biomed Anal 49(4): 1109-1114. 
Blivet-Van Eggelpoel MJ, Chettouh H, Fartoux L, Aoudjehane L, Barbu V, Rey C, Priam S, Housset C, Rosmorduc O and Desbois-Mouthon C (2012) Epidermal growth factor receptor and HER-3 restrict cell response to sorafenib in hepatocellular carcinoma cells. $J$ Hepatol 57(1): 108-115.

Bort A, Sanchez BG, Mateos-Gomez PA, Vara-Ciruelos D, Rodriguez-Henche N and Diaz-Laviada I (2019) Targeting AMP-activated kinase impacts hepatocellular cancer stem cells induced by long-term treatment with sorafenib. Mol Oncol 13(5): 1311-1331.

Cai H, Everett RS and Thakker DR (2019) Efficacious dose of metformin for breast cancer therapy is determined by cation transporter expression in tumours. Br J Pharmacol 176(15): 2724-2735.

Caruso S, Calatayud AL, Pilet J, La Bella T, Rekik S, Imbeaud S, Letouze E, Meunier L, Bayard Q, Rohr-Udilova N, Peneau C, Grasl-Kraupp B, de Koning L, Ouine B, BioulacSage P, Couchy G, Calderaro J, Nault JC, Zucman-Rossi J and Rebouissou S (2019) Analysis of Liver Cancer Cell Lines Identifies Agents With Likely Efficacy Against Hepatocellular Carcinoma and Markers of Response. Gastroenterology 157(3): 760-776.

Casadei Gardini A, Faloppi L, De Matteis S, Foschi FG, Silvestris N, Tovoli F, Palmieri V, Marisi G, Brunetti O, Vespasiani-Gentilucci U, Perrone G, Valgiusti M, Granato AM, Ercolani G, Negrini G, Tamburini E, Aprile G, Passardi A, Santini D, Cascinu S, Frassineti GL and Scartozzi M (2017) Metformin and insulin impact on clinical outcome in patients with advanced hepatocellular carcinoma receiving sorafenib: Validation study and biological rationale. Eur J Cancer 86: 106-114.

Casadei Gardini A, Marisi G, Scarpi E, Scartozzi M, Faloppi L, Silvestris N, Masi G, Vivaldi C, Brunetti O, Tamberi S, Foschi FG, Tamburini E, Tenti E, Ricca Rosellini S, Ulivi P, Cascinu S, Nanni O and Frassineti GL (2015) Effects of metformin on clinical outcome in diabetic patients with advanced HCC receiving sorafenib. Expert Opin Pharmacother 16(18): $2719-2725$.

Cauchy F, Mebarki M, Leporq B, Laouirem S, Albuquerque M, Lambert S, Bourgoin P, Soubrane O, Van Beers BE, Faivre S, Bedossa P and Paradis V (2017) Strong 
antineoplastic effects of metformin in preclinical models of liver carcinogenesis. Clin Sci (Lond) 131(1): 27-36.

Chen HP, Shieh JJ, Chang CC, Chen TT, Lin JT, Wu MS, Lin JH and Wu CY (2013) Metformin decreases hepatocellular carcinoma risk in a dose-dependent manner: populationbased and in vitro studies. Gut 62(4): 606-615.

Cheng J, Huang T, Li Y, Guo Y, Zhu Y, Wang Q, Tan X, Chen W, Zhang Y, Cheng W, Yamamoto T, Jing X and Huang J (2014) AMP-activated protein kinase suppresses the in vitro and in vivo proliferation of hepatocellular carcinoma. PLoS One 9(4): e93256.

Covell DG (2017) A data mining approach for identifying pathway-gene biomarkers for predicting clinical outcome: A case study of erlotinib and sorafenib. PLoS One 12(8): e0181991.

Croft D, O'Kelly G, Wu G, Haw R, Gillespie M, Matthews L, Caudy M, Garapati P, Gopinath G, Jassal B, Jupe S, Kalatskaya I, Mahajan S, May B, Ndegwa N, Schmidt E, Shamovsky V, Yung C, Birney E, Hermjakob H, D'Eustachio P and Stein L (2011) Reactome: a database of reactions, pathways and biological processes. Nucleic Acids Res 39(Database issue): D691-697.

Cunha V, Cotrim HP, Rocha R, Carvalho K and Lins-Kusterer L (2020) Metformin in the prevention of hepatocellular carcinoma in diabetic patients: A systematic review. Ann Hepatol 19(3): 232-237.

Desbois-Mouthon C, Baron A, Blivet-Van Eggelpoel MJ, Fartoux L, Venot C, Bladt F, Housset C and Rosmorduc O (2009) Insulin-Like Growth Factor-1 Receptor Inhibition Induces a Resistance Mechanism via the Epidermal Growth Factor Receptor/HER3/AKT Signaling Pathway: Rational Basis for Cotargeting Insulin-Like Growth Factor-1 Receptor and Epidermal Growth Factor Receptor in Hepatocellular Carcinoma. Clinical Cancer Research 15(17): 5445-5456.

Dowling RJ, Lam S, Bassi C, Mouaaz S, Aman A, Kiyota T, Al-Awar R, Goodwin PJ and Stambolic V (2016) Metformin Pharmacokinetics in Mouse Tumors: Implications for Human Therapy. Cell metabolism 23(4): 567-568. 
Edginton AN, Zimmerman EI, Vasilyeva A, Baker SD and Panetta JC (2016) Sorafenib metabolism, transport, and enterohepatic recycling: physiologically based modeling and simulation in mice. Cancer Chemother Pharmacol 77(5): 1039-1052.

European Medecine Agency (EMA). Nexavar: European Public Assessment Report (EPAR) - Scientific discussion. [on line] March, $3^{\text {st }}, 2007$. Available: https://www.ema.europa.eu/en/documents/scientific-discussion/nexavar-epar-scientific-

\section{discussion en.pdf}

Ferlay J, Colombet M, Soerjomataram I, Mathers C, Parkin DM, Pineros M, Znaor A and Bray F (2019) Estimating the global cancer incidence and mortality in 2018: GLOBOCAN sources and methods. Int J Cancer 144(8): 1941-1953.

Foretz M, Hebrard S, Leclerc J, Zarrinpashneh E, Soty M, Mithieux G, Sakamoto K, Andreelli F and Viollet B (2010) Metformin inhibits hepatic gluconeogenesis in mice independently of the LKB1/AMPK pathway via a decrease in hepatic energy state. $J$ Clin Invest 120(7): 2355-2369.

Goumard C, Desbois-Mouthon C, Wendum D, Calmel C, Merabtene F, Scatton O and Praz F (2017) Low Levels of Microsatellite Instability at Simple Repeated Sequences Commonly Occur in Human Hepatocellular Carcinoma. Cancer Genomics Proteomics 14(5): 329-339.

Groenendijk FH, Mellema WW, van der Burg E, Schut E, Hauptmann M, Horlings HM, Willems SM, van den Heuvel MM, Jonkers J, Smit EF and Bernards R (2015) Sorafenib synergizes with metformin in NSCLC through AMPK pathway activation. Int J Cancer 136(6): 1434-1444.

Guo Z, Cao M, You A, Gao J, Zhou H, Li H, Cui Y, Fang F, Zhang W, Song T, Li Q, Zhu X, Sun $\mathrm{H}$ and Zhang T (2016) Metformin inhibits the prometastatic effect of sorafenib in hepatocellular carcinoma by upregulating the expression of TIP30. Cancer Sci 107(4): 507513.

Hamoudi RA, Appert A, Ye H, Ruskone-Fourmestraux A, Streubel B, Chott A, Raderer M, Gong L, Wlodarska I, De Wolf-Peeters C, MacLennan KA, de Leval L, Isaacson PG and 
Du MQ (2010) Differential expression of NF-kappaB target genes in MALT lymphoma with and without chromosome translocation: insights into molecular mechanism. Leukemia 24(8): $1487-1497$.

Haouala A, Rumpold H, Untergasser G, Buclin T, Ris HB, Widmer N and Decosterd LA (2010) siRNA-mediated knock-down of P-glycoprotein expression reveals distinct cellular disposition of anticancer tyrosine kinases inhibitors. Drug Metab Lett 4(2): 114-119.

Heishi M, Ichihara J, Teramoto R, Itakura Y, Hayashi K, Ishikawa H, Gomi H, Sakai J, Kanaoka M, Taiji M and Kimura T (2006) Global gene expression analysis in liver of obese diabetic db/db mice treated with metformin. Diabetologia 49(7): 1647-1655.

Herraez E, Lozano E, Macias RI, Vaquero J, Bujanda L, Banales JM, Marin JJ and Briz O (2013) Expression of SLC22A1 variants may affect the response of hepatocellular carcinoma and cholangiocarcinoma to sorafenib. Hepatology 58(3): 1065-1073.

Hou M, Venier N, Sugar L, Musquera M, Pollak M, Kiss A, Fleshner N, Klotz L and Venkateswaran V (2010) Protective effect of metformin in CD1 mice placed on a high carbohydrate-high fat diet. Biochem Biophys Res Commun 397(3): 537-542.

Hu, Zeng Z, Xia Q, Liu Z, Feng X, Chen J, Huang M, Chen L, Fang Z, Liu Q, Zeng H, Zhou X and Liu J (2019) Metformin attenuates hepatoma cell proliferation by decreasing glycolytic flux through the HIF-1alpha/PFKFB3/PFK1 pathway. Life Sci 239: 116966.

Hu S, Chen Z, Franke R, Orwick S, Zhao M, Rudek MA, Sparreboom A and Baker SD (2009) Interaction of the multikinase inhibitors sorafenib and sunitinib with solute carriers and ATP-binding cassette transporters. Clin Cancer Res 15(19): 6062-6069.

Huang WC, Hsieh YL, Hung CM, Chien PH, Chien YF, Chen LC, Tu CY, Chen CH, Hsu SC, Lin YM and Chen YJ (2013) BCRP/ABCG2 inhibition sensitizes hepatocellular carcinoma cells to sorafenib. PLoS One 8(12): e83627.

Irizarry RA, Bolstad BM, Collin F, Cope LM, Hobbs B and Speed TP (2003) Summaries of Affymetrix GeneChip probe level data. Nucleic Acids Res 31(4): e15. 
Jiang C, Zhang Y, Yu HF, Yu XT, Zhou SJ and Tan YF (2012) Expression of ADAM8 and its clinical values in diagnosis and prognosis of hepatocellular carcinoma. Tumour Biol 33(6): 2167-2172.

Kanehisa M and Goto S (2000) KEGG: kyoto encyclopedia of genes and genomes. Nucleic Acids Res 28(1): 27-30.

Karbownik A, Szkutnik-Fiedler D, Czyrski A, Kostewicz N, Kaczmarska P, Bekier M, Stanislawiak-Rudowicz J, Karazniewicz-Lada M, Wolc A, Glowka F, Grzeskowiak E and Szalek E (2020) Pharmacokinetic Interaction between Sorafenib and Atorvastatin, and Sorafenib and Metformin in Rats. Pharmaceutics 12(7).

Kiriyama S, Yokoyama S, Ueno M, Hayami S, leda J, Yamamoto N, Yamaguchi S, Mitani Y, Nakamura Y, Tani M, Mishra L, Shively JE and Yamaue H (2014) CEACAM1 long cytoplasmic domain isoform is associated with invasion and recurrence of hepatocellular carcinoma. Ann Surg Oncol 21 Suppl 4: S505-514.

Lalau JD, Lemaire-Hurtel AS and Lacroix C (2011) Establishment of a database of metformin plasma concentrations and erythrocyte levels in normal and emergency situations. Clin Drug Investig 31(6): 435-438.

Ling S, Song L, Fan N, Feng T, Liu L, Yang X, Wang M, Li Y, Tian Y, Zhao F, Liu Y, Huang Q, Hou Z, Xu F, Shi L and Li Y (2017) Combination of metformin and sorafenib suppresses proliferation and induces autophagy of hepatocellular carcinoma via targeting the mTOR pathway. Int J Oncol 50(1): 297-309.

Marisi G, Cucchetti A, Ulivi P, Canale M, Cabibbo G, Solaini L, Foschi FG, De Matteis S, Ercolani G, Valgiusti M, Frassineti GL, Scartozzi M and Casadei Gardini A (2018) Ten years of sorafenib in hepatocellular carcinoma: Are there any predictive and/or prognostic markers? World J Gastroenterol 24(36): 4152-4163.

Miyoshi H, Kato K, Iwama H, Maeda E, Sakamoto T, Fujita K, Toyota Y, Tani J, Nomura T, Mimura S, Kobayashi M, Morishita A, Kobara H, Mori H, Yoneyama H, Deguchi A, Himoto T, Kurokohchi K, Okano K, Suzuki Y, Murao K and Masaki T (2014) Effect of the 
anti-diabetic drug metformin in hepatocellular carcinoma in vitro and in vivo. Int $J$ Oncol 45(1): 322-332.

Nadella KS, Jones GN, Trimboli A, Stratakis CA, Leone G and Kirschner LS (2008) Targeted deletion of Prkar1a reveals a role for protein kinase A in mesenchymal-to-epithelial transition. Cancer Res 68(8): 2671-2677.

Park DJ, Sung PS, Kim JH, Lee GW, Jang JW, Jung ES, Bae SH, Choi JY and Yoon SK (2020) EpCAM-high liver cancer stem cells resist natural killer cell-mediated cytotoxicity by upregulating CEACAM1. J Immunother Cancer 8(1).

Poller B, Wagenaar E, Tang SC and Schinkel AH (2011) Double-transduced MDCKII cells to study human P-glycoprotein (ABCB1) and breast cancer resistance protein (ABCG2) interplay in drug transport across the blood-brain barrier. Molecular pharmaceutics 8(2): 571 582.

Saito T, Chiba T, Yuki K, Zen Y, Oshima M, Koide S, Motoyama T, Ogasawara S, Suzuki E, Ooka Y, Tawada A, Tada M, Kanai F, Takiguchi Y, Iwama A and Yokosuka O (2013) Metformin, a diabetes drug, eliminates tumor-initiating hepatocellular carcinoma cells. PLoS One 8(7): e70010.

Schulte L, Scheiner B, Voigtlander T, Koch S, Schweitzer N, Marhenke S, Ivanyi P, Manns MP, Rodt T, Hinrichs JB, Weinmann A, Pinter M, Vogel A and Kirstein MM (2019) Treatment with metformin is associated with a prolonged survival in patients with hepatocellular carcinoma. Liver Int 39(4): 714-726.

Singhal SS, Sehrawat A, Sahu M, Singhal P, Vatsyayan R, Rao Lelsani PC, Yadav S and Awasthi S (2010) Rlip76 transports sunitinib and sorafenib and mediates drug resistance in kidney cancer. Int J Cancer 126(6): 1327-1338.

Swift B, Nebot N, Lee JK, Han T, Proctor WR, Thakker DR, Lang D, Radtke M, Gnoth MJ and Brouwer KL (2013) Sorafenib hepatobiliary disposition: mechanisms of hepatic uptake and disposition of generated metabolites. Drug metabolism and disposition: the biological fate of chemicals 41(6): 1179-1186. 
Tai WT, Cheng AL, Shiau CW, Huang HP, Huang JW, Chen PJ and Chen KF (2011) Signal transducer and activator of transcription 3 is a major kinase-independent target of sorafenib in hepatocellular carcinoma. Journal of hepatology 55(5): 1041-1048.

Tang SC, de Vries N, Sparidans RW, Wagenaar E, Beijnen JH and Schinkel AH (2013) Impact of P-glycoprotein (ABCB1) and breast cancer resistance protein (ABCG2) gene dosage on plasma pharmacokinetics and brain accumulation of dasatinib, sorafenib, and sunitinib. The Journal of pharmacology and experimental therapeutics 346(3): 486-494.

Tsai HH, Lai HY, Chen YC, Li CF, Huang HS, Liu HS, Tsai YS and Wang JM (2017) Metformin promotes apoptosis in hepatocellular carcinoma through the CEBPD-induced autophagy pathway. Oncotarget 8(8): 13832-13845.

Tsunematsu H, Tatsumi T, Kohga K, Yamamoto M, Aketa H, Miyagi T, Hosui A, Hiramatsu N, Kanto T, Hayashi N and Takehara T (2012) Fibroblast growth factor-2 enhances NK sensitivity of hepatocellular carcinoma cells. Int J Cancer 130(2): 356-364.

Wilhelm SM, Adnane L, Newell P, Villanueva A, Llovet JM and Lynch M (2008) Preclinical overview of sorafenib, a multikinase inhibitor that targets both Raf and VEGF and PDGF receptor tyrosine kinase signaling. Mol Cancer Ther 7(10): 3129-3140.

Yarchoan M, Agarwal P, Villanueva A, Rao S, Dawson LA, Llovet JM, Finn RS, Groopman JD, El-Serag HB, Monga SP, Wang XW, Karin M, Schwartz RE, Tanabe KK, Roberts LR, Gunaratne PH, Tsung A, Brown KA, Lawrence TS, Salem R, Singal AG, Kim AK, Rabiee A, Resar L, Hoshida Y, He AR, Ghoshal K, Ryan PB, Jaffee EM, Guha C, Mishra L, Coleman CN and Ahmed MM (2019) Recent Developments and Therapeutic Strategies against Hepatocellular Carcinoma. Cancer Res 79(17): 4326-4330.

Yoshikawa M, Morine Y, Ikemoto T, Imura S, Higashijima J, Iwahashi S, Saito YU, Takasu C, Yamada S, Ishikawa D, Teraoku H, Takata A, Yoshimoto T and Shimada M (2017) Elevated Preoperative Serum CEA Level Is Associated with Poor Prognosis in Patients with Hepatocellular Carcinoma Through the Epithelial-Mesenchymal Transition. Anticancer Res 37(3): 1169-1175. 
You A, Cao M, Guo Z, Zuo B, Gao J, Zhou H, Li H, Cui Y, Fang F, Zhang W, Song T, Li Q, Zhu X, Yin $H$, Sun $H$ and Zhang $T$ (2016) Metformin sensitizes sorafenib to inhibit postoperative recurrence and metastasis of hepatocellular carcinoma in orthotopic mouse models. J Hematol Oncol 9: 20.

Younossi ZM, Golabi P, de Avila L, Minhui Paik J, Srishord M, Fukui N, Qiu Y, Burns L, Afendy A and Nader F (2019) The Global Epidemiology of NAFLD and NASH in Patients with type 2 diabetes: A Systematic Review and Meta-analysis. J Hepatol.

Zhang X, Harmsen WS, Mettler TA, Kim WR, Roberts RO, Therneau TM, Roberts LR and Chaiteerakij R (2014) Continuation of metformin use after a diagnosis of cirrhosis significantly improves survival of patients with diabetes. Hepatology 60(6): 2008-2016.

Zhang Y, Zha TZ, Hu BS, Jiang C, Ge ZJ, Zhang K and Tan YF (2013) High expression of ADAM8 correlates with poor prognosis in hepatocellular carcinoma. Surgeon 11(2): $67-71$

Zheng L, Yang W, Wu F, Wang C, Yu L, Tang L, Qiu B, Li Y, Guo L, Wu M, Feng G, Zou D and Wang H (2013) Prognostic significance of AMPK activation and therapeutic effects of metformin in hepatocellular carcinoma. Clin Cancer Res 19(19): 5372-5380.

Zhou YY, Zhu GQ, Liu T, Zheng JN, Cheng Z, Zou TT, Braddock M, Fu SW and Zheng MH (2016) Systematic Review with Network Meta-Analysis: Antidiabetic Medication and Risk of Hepatocellular Carcinoma. Sci Rep 6: 33743.

Zimmerman El, Hu S, Roberts JL, Gibson AA, Orwick SJ, Li L, Sparreboom A and Baker SD (2013) Contribution of OATP1B1 and OATP1B3 to the disposition of sorafenib and sorafenib-glucuronide. Clin Cancer Res 19(6): 1458-1466. 


\section{Footnotes}

a) This work was supported by grants from Institut National de la Santé et de la Recherche Médicale (INSERM); Cancéropôle Ile de France; Institut National du Cancer (INCa-DGOS_5790); and the University of Sharjah (Competitive Grant no. 1701110321-P). The authors declare no conflict of interest.

b) Reprint requests should be directed to Dr Christèle Desbois-Mouthon, Centre de Recherche des Cordeliers, INSERM UMR_S1138, 15 rue de l'école de médecine, 75006 Paris, France or by email inquiry to christele.desboismouthon@inserm.fr

c) Author affiliations 1 Department of Pharmacy Practice and Pharmacotherapeutics, College of Pharmacy, University of Sharjah, Sharjah, United Arab Emirates; ${ }^{2}$ Centre de Recherche Saint-Antoine, Sorbonne Université, INSERM, F-750012 Paris, France; ${ }^{3}$ Département de Pharmacocinétique et Pharmacochimie, Hôpital Cochin, AP-HP, CARPEM, F75014 Paris, France UMR8038 CNRS, U1268 INSERM, Faculté de Pharmacie, Université de Paris, PRES Sorbonne Paris Cité, F-75006 Paris, France ; ${ }^{5}$ Centre National de la Recherche Scientifique, Paris, France ; 6 Department of Clinical Sciences, College of Medicine, University of Sharjah, Sharjah, United Arab Emirates; ${ }^{7}$ Division of Surgery and Interventional Science, UCL, London, United Kingdom; ${ }^{8}$ Centre de Recherche des Cordeliers, Sorbonne Université, INSERM, Université de Paris, F-75006 Paris, France 


\section{Figure legends}

Figure 1. Effects of the concomitant and sequential combinations of metformin and sorafenib on tumor growth in a HCC xenograft model.

A, a low dose of metformin $(50 \mathrm{mg} / \mathrm{kg} / \mathrm{d}, \mathrm{n}=7)$ and vehicle $(\mathrm{n}=7)$ were administrated to six week-old athymic mice four days before s.c. xenografts with $2 \times 10^{6}$ PLC/PRF5 cells and maintained during the next 15 days. The evolution of tumor volumes over the 15 days of treatment is presented. B, tumor weights at sacrifice. C, six week-old athymic mice were inoculated s.c. with $2 \times 10^{6}$ PLC/PRF5 cells. Once tumor volumes reached $250 \mathrm{~mm}^{3}$, mice were treated by gavage with vehicles (control, $\mathrm{n}=19$ ), sorafenib alone (15 mg/kg/day, $\mathrm{n}=10$ ), metformin alone (50 mg/kg/day, $\mathrm{n}=14$ ), metformin combined to sorafenib (concomitant schedule, $n=8$ ) or metformin followed $6 \mathrm{~h}$ later by sorafenib (sequential schedule, $\mathrm{n}=14$ ). The evolution of tumor volumes over the 15 days of treatment is presented. Inset: representative photographs of tumors at sacrifice after concomitant or sequential treatment. D, relative tumor volumes (RTV) were calculated for each group using the formula: TVd15/TVd1, where TVd15 and TVd1 are the mean tumor volumes at day 15 and day 1, respectively. $\mathrm{E}$, tumor weights at sacrifice. Data are mean $\pm \mathrm{SD}$. $P$ values were determined using one-way ANOVA relative to the control condition.

Figure 2. Effects of the concomitant and sequential combinations of metformin and sorafenib on cell viability in human HCC cell lines.

A, PLC/PRF5, HepG2, Hep3B and Huh7 cell lines were seeded in 24-well plates (3 $\times$ $10^{5}$ cells per well) and allowed to proliferate for $24 \mathrm{~h}$ in complete medium. Then cells were incubated for a further $72 \mathrm{~h}$ in the presence or not of metformin $(1 \mathrm{mM})$, sorafenib $(1 \mu \mathrm{M})$, metformin combined to sorafenib or metformin followed $6 \mathrm{~h}$ later by 
sorafenib. At the end of the treatment period, cell viability was measured using the MTT assay. Data are mean \pm SD of three independent experiments performed in 8 determinations. $P$ values were determined using one-way ANOVA relative to the concomitant condition. $P$ values for other multiple comparisons are presented in supplementary Table S1. B, similar experiments were performed in PLC/PRF5 cells treated with different concentrations of metformin $(0-0.5-1-2-3 \mathrm{mM})$ in combination with sorafenib (0-1-2 $\mu \mathrm{M})$. Data are mean of two independent experiments performed in 8 determinations.

Figure 3. Effects of the concomitant and sequential combinations of metformin and sorafenib on cell proliferation in human HCC cell lines.

PLC/PRF5 and Huh7 cell lines were seeded in 24 -well plates $\left(3 \times 10^{5}\right.$ cells per well) and allowed to proliferate for $24 \mathrm{~h}$ in complete medium. Then cells were incubated for a further $72 \mathrm{~h}$ in the presence or not of metformin $(1 \mathrm{mM})$, sorafenib $(1 \mu \mathrm{M})$, metformin combined to sorafenib or metformin followed $6 \mathrm{~h}$ later by sorafenib. At the end of the treatment period, cell proliferation was measured by cell counting $(A)$ and staining DNA with $0.1 \%$ crystal violet $(B)$. Data are mean of two independent experiments performed in 8 determinations.

Figure 4. Effects of metformin on the expression of efflux/influx transporters and sorafenib disposal in HCC cell lines.

$A$ and $B$, total RNA was extracted from human hepatocytes in primary culture and HCC cell lines and quantitative measurements of transcripts coding for influx and efflux transporters were performed by real-time PCR. Values are mean \pm SD of four independent experiments. $\mathrm{C}$ and $\mathrm{D}$, uptake of $\left[{ }^{3} \mathrm{H}\right]$ sorafenib over 10 min in Huh7 cells 
pre-treated during $6 \mathrm{~h}$ in the presence of metformin $(0-0.5-1-2-3-4 \mathrm{mM})$ at $37^{\circ} \mathrm{C}$ or $4^{\circ} \mathrm{C}$. Data are mean of two independent experiments performed in triplicates.

Figure 5. Effects of the concomitant and sequential combinations of metformin and sorafenib on the stimulation of AMPK phosphorylation in human HCC cell lines.

A, PLC/PRF5 and Huh7 cell lines were seeded in 24 -well plates $\left(3 \times 10^{5}\right.$ cells per well) and allowed to proliferate for $24 \mathrm{~h}$ in complete medium. Then cells were incubated for a further $72 \mathrm{~h}$ in the presence or not of AICAR $(0.5 \mathrm{mM})$, sorafenib (1 $\mu \mathrm{M})$, AICAR combined to sorafenib or AICAR followed $6 \mathrm{~h}$ later by sorafenib. At the end of the treatment period, cell viability was measured using the MTT assay. Data are mean $\pm \mathrm{SD}$ of three independent experiments performed in 8 determinations. $P$ values were determined using one-way ANOVA relative to the concomitant condition. $P$ values for other multiple comparisons are presented in supplementary Table S1. B, whole-cell lysates were analyzed by Western blotting for phosphorylated and total levels of AMPK. Blots are representative of two independent experiments. Values depict the relative PAMPK/AMPK activation ratio (AR) evaluated by scanning densitometry from the two independent experiments.

Figure 6. Examples of signatures differentially modulated in xenografted tumors treated with concomitant and sequential metformin/sorafenib administration in comparison with control tumors.

A, Venn diagram showing the numbers of genes differentially expressed between untreated tumors $(n=3)$ and tumors obtained after sequential $(n=3)$ or concomitant $(n=3)$ administration. 1035 genes were identified to be differentially expressed 
between control and concomitant treatments, 771 genes between control and sequential treatments, and 1051 genes between sequential $(n=3)$ and concomitant treatments. Among these differentially expressed genes, 193 genes were commonly altered by both types of treatments, while 842 genes were altered by the concomitant treatment only and 578 genes by the sequential treatment. B, flowchart outlining the steps of the bioinformatics approach to identify differentially expressed genes in concomitant and sequential treatments compared to controls. RNA samples were hybridized to Human Clariom ${ }^{\mathrm{TM}} \mathrm{S}$ GeneChip. Following normalization using Signal Space Transformation-RMA (SST-RMA), differential expression was carried out using eBayes function and One-Way Anova statistical analysis. The analysis was carried out using Transcriptome Analysis Console software. The differentially expressed genes were then subjected to absolute GSEA searching through more than 10,000 different cellular pathways. C, examples of signatures differentially modulated in xenografted tumors treated with concomitant and sequential metformin/sorafenib administration in comparison with control tumors. Upper, GSEA of GO_G_PROTEIN_COUPLED_RECEPTOR_ACTIVITY (GO:0007186) in HCC xenografts treated with concomitant combination of metformin and sorafenib in comparison with control group; middle, GSEA of GO_REGULATION_OF_PHOSPHORUS_METABOLIC_PROCESS (GO:0051174) in HCC xenografts treated with sequential combination of metformin followed by sorafenib in comparison with control group; lower, GSEA of BENPORATH_EED_TARGETS (M7617) in HCC xenografts treated with sequential combination of metformin followed by sorafenib in comparison with concomitant treatment. 


\section{Tables}

Table 1. Plasma concentrations of metformin and sorafenib

\begin{tabular}{|l|c|c|c|c|}
\cline { 2 - 5 } \multicolumn{1}{c|}{} & \multicolumn{2}{c|}{ metformin (mg/L) } & \multicolumn{2}{c|}{ sorafenib (mg/L) } \\
\cline { 2 - 5 } \multicolumn{1}{c|}{} & $2 h$ & $4 h$ & $2 h$ & $6 h$ \\
\hline $\begin{array}{l}\text { Monotherapy } \\
(n=3)\end{array}$ & $0.56(0.36-0.73)$ & $0.22(0.18-0.49)$ & $2.98(1.34-3.23)$ & $0.61(0.61-0.77)$ \\
\hline $\begin{array}{l}\text { Concomitant } \\
(n=4)\end{array}$ & & & $2.04(1.84-3.08)$ & $1.06(0.63-1.38)$ \\
\hline $\begin{array}{l}\text { sequential } \\
(n=4)\end{array}$ & & & $2.07(1.68-5.22)$ & \\
\hline $\begin{array}{l}\text { sequential } \\
(n=3)\end{array}$ & & & $3.16(2.03-5.20)$ & \\
\hline
\end{tabular}

Values are median (IQR); significances between sorafenib, concomitant and sequential groups were tested using Kruskal-Wallis test. *, metformin was administrated $2 \mathrm{~h}$ before sorafenib. ${ }^{* *}$, metformin was administrated $4 \mathrm{~h}$ before sorafenib 
Table 2. Tumor growth inhibition rates

\begin{tabular}{lc}
\hline & $\begin{array}{c}\text { \%TGI* } \\
(\text { day 15) }\end{array}$ \\
\hline Control $(n=19)$ & \\
\hline Metformin $(n=14)$ & 11.7 \\
\hline Sorafenib $(n=10)$ & 42.3 \\
\hline Concomitant $(n=8)$ & 59.5 \\
\hline Sequential $(n=14)$ & 15.4 \\
\hline
\end{tabular}

*Tumor growth inhibition (TGI) rates were calculated using the formula: (1$T V t / T V c)^{*} 100$, where TVt and TVc are the mean tumor volumes of treated and control groups, respectively. 
Figure 6

a

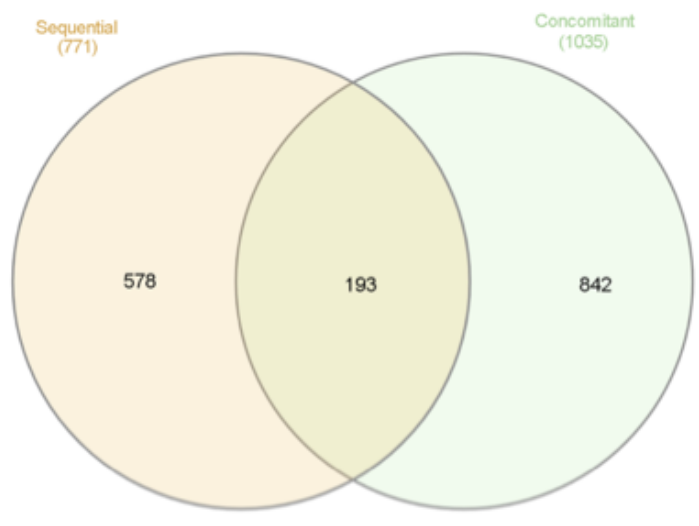

b Control Vs Concomitant ( $n=3$ )

Control vs Sequential $(n=3)$ Sequential ys Concomitant

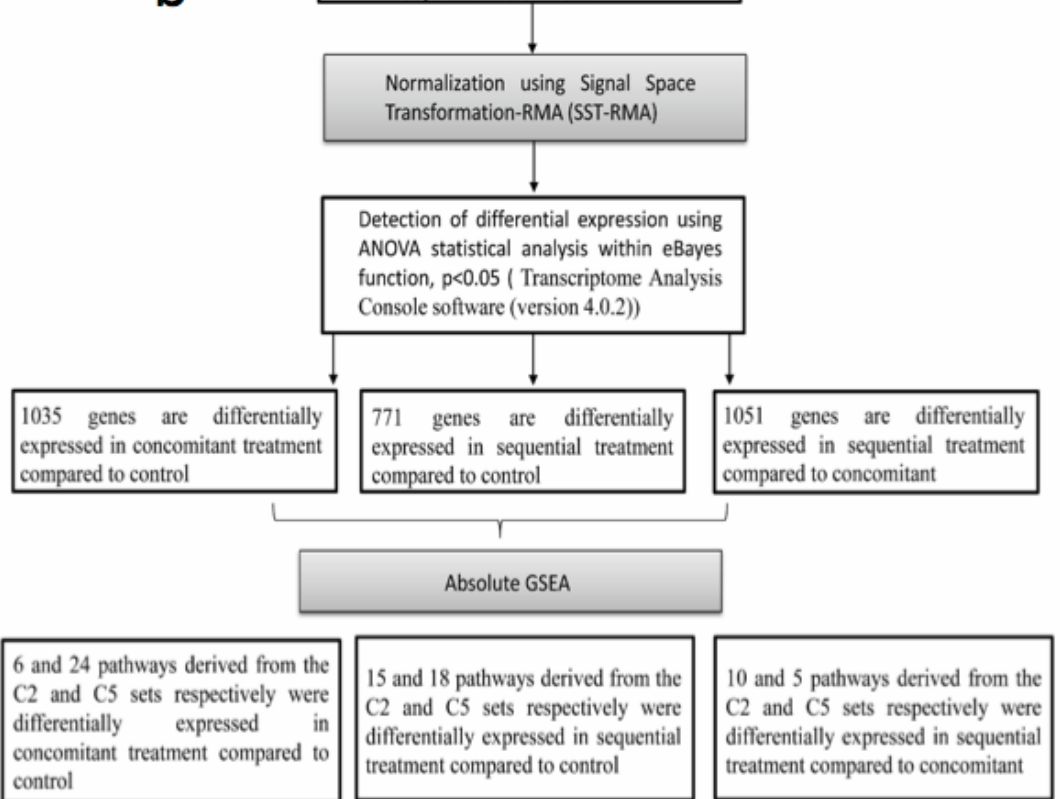

C

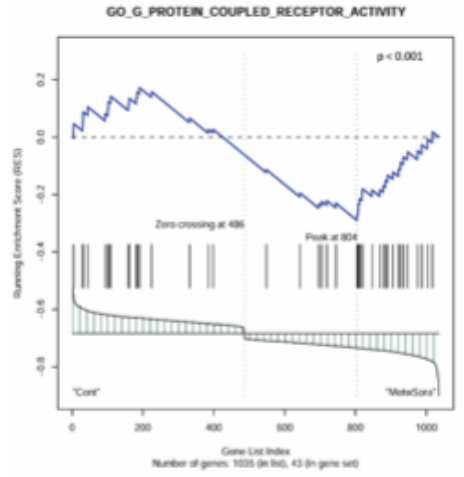

GO REGULATION OF PHOSPHORUS METABOUC PROCESS

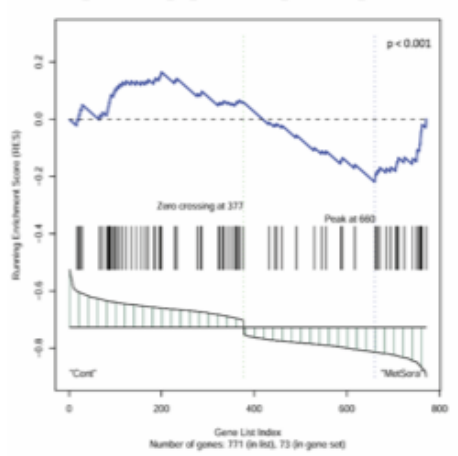

BENPORATH EED TARGETS

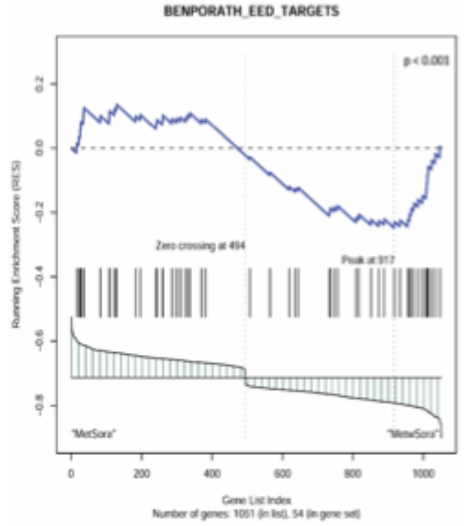

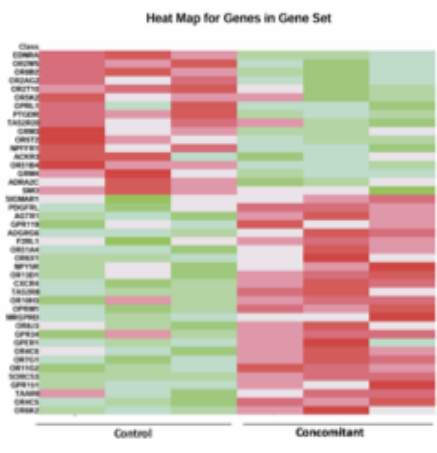

Heat Map for Genes in Gene Set

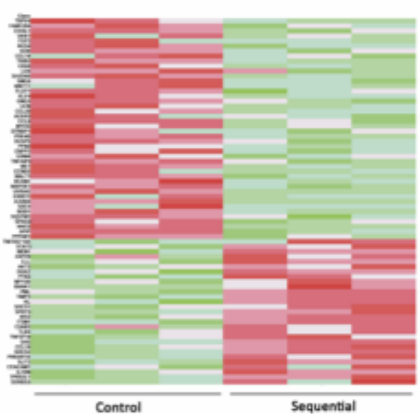

Heat Map tor Genes in Gene Set

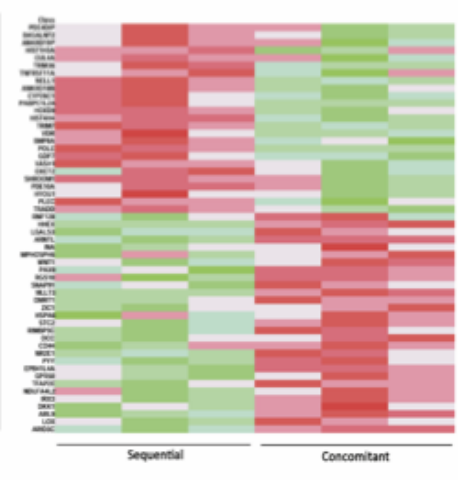


a

\section{PLC/PRF5}

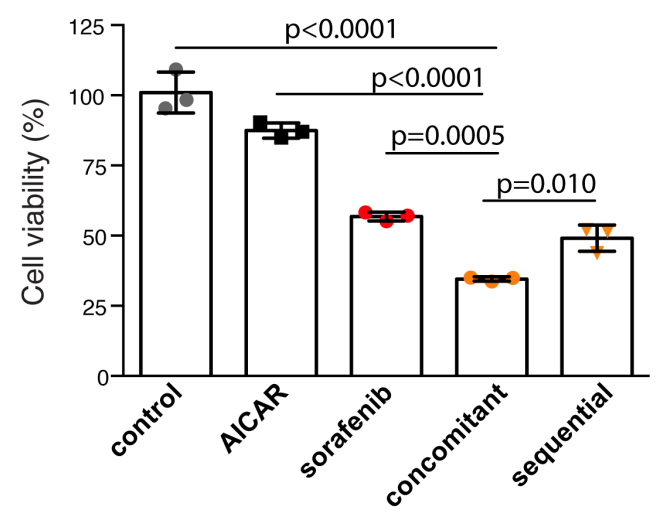

b
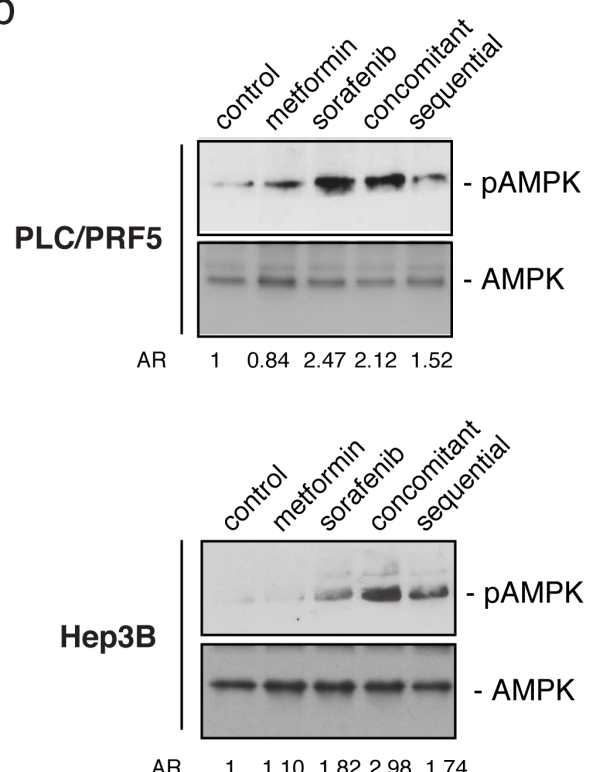

Huh7
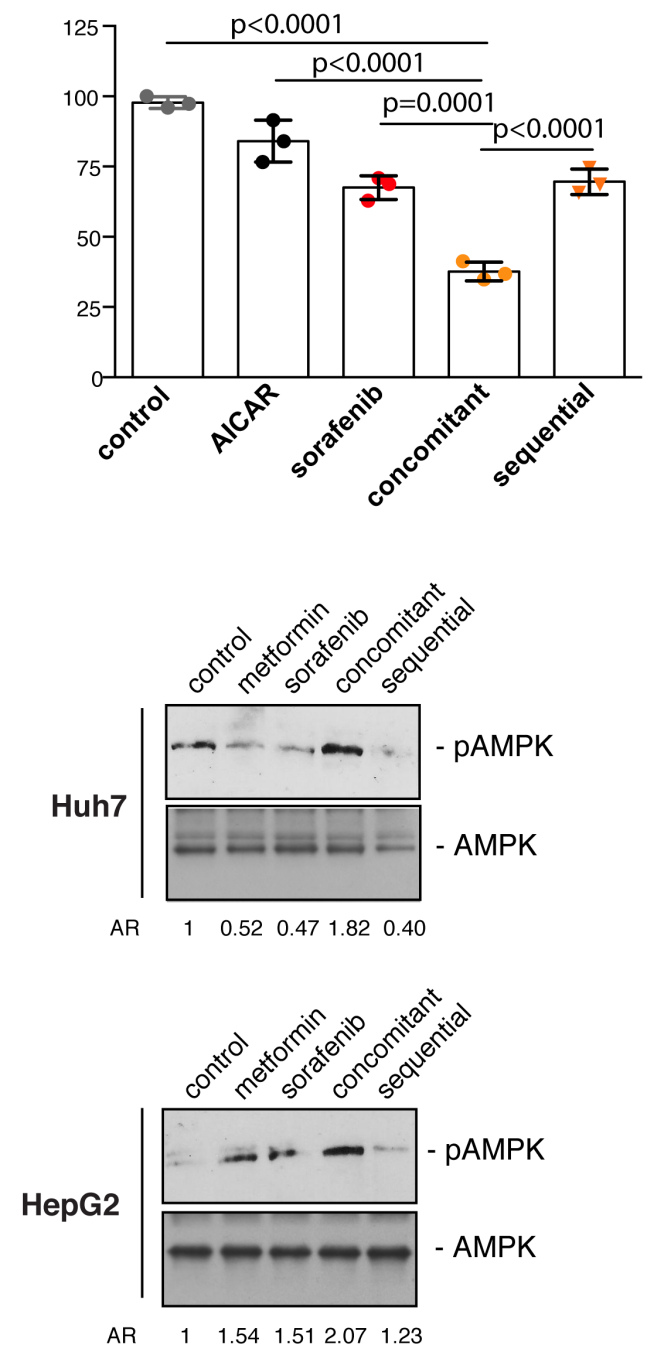
Figure 4

a
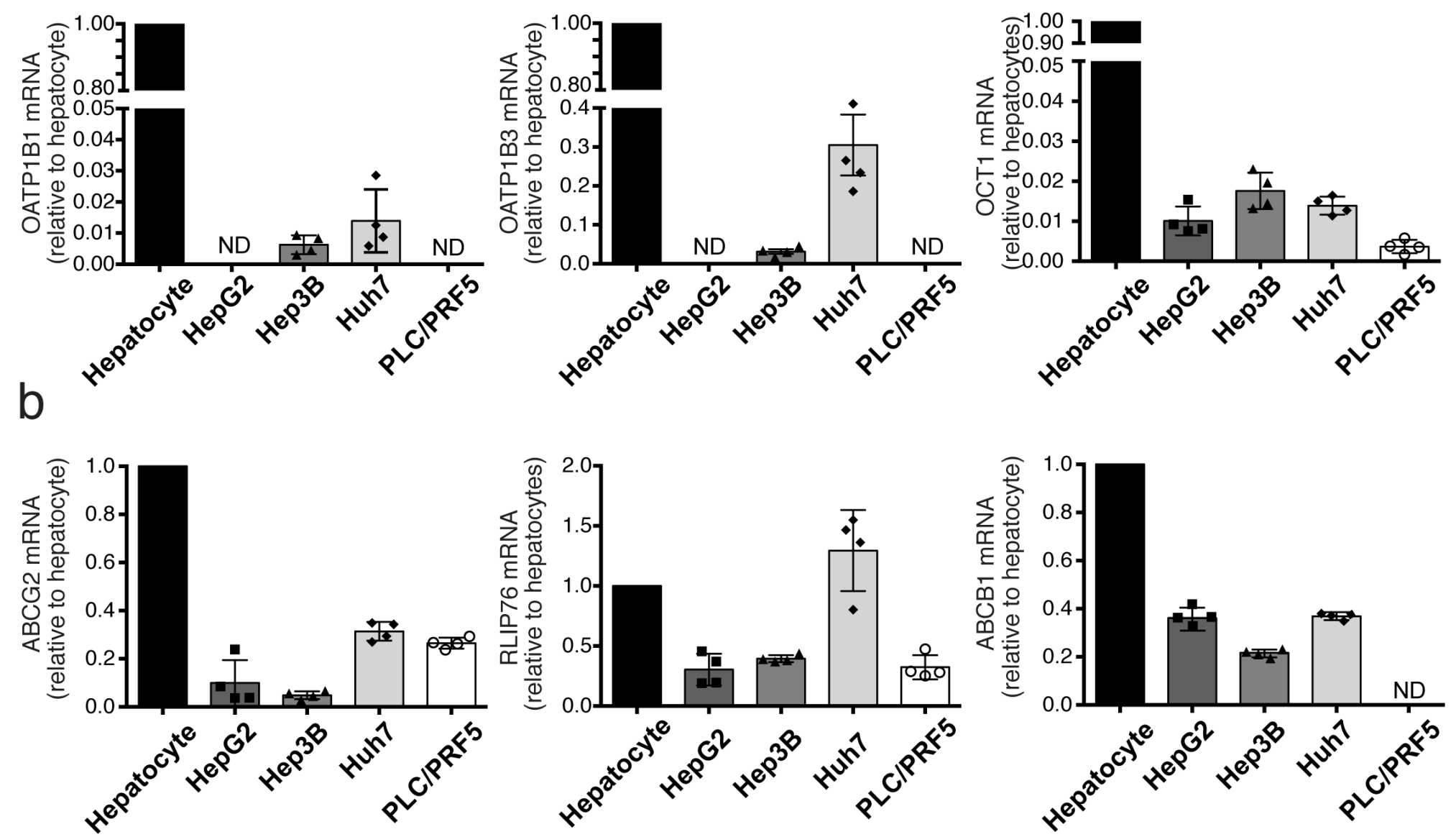

C
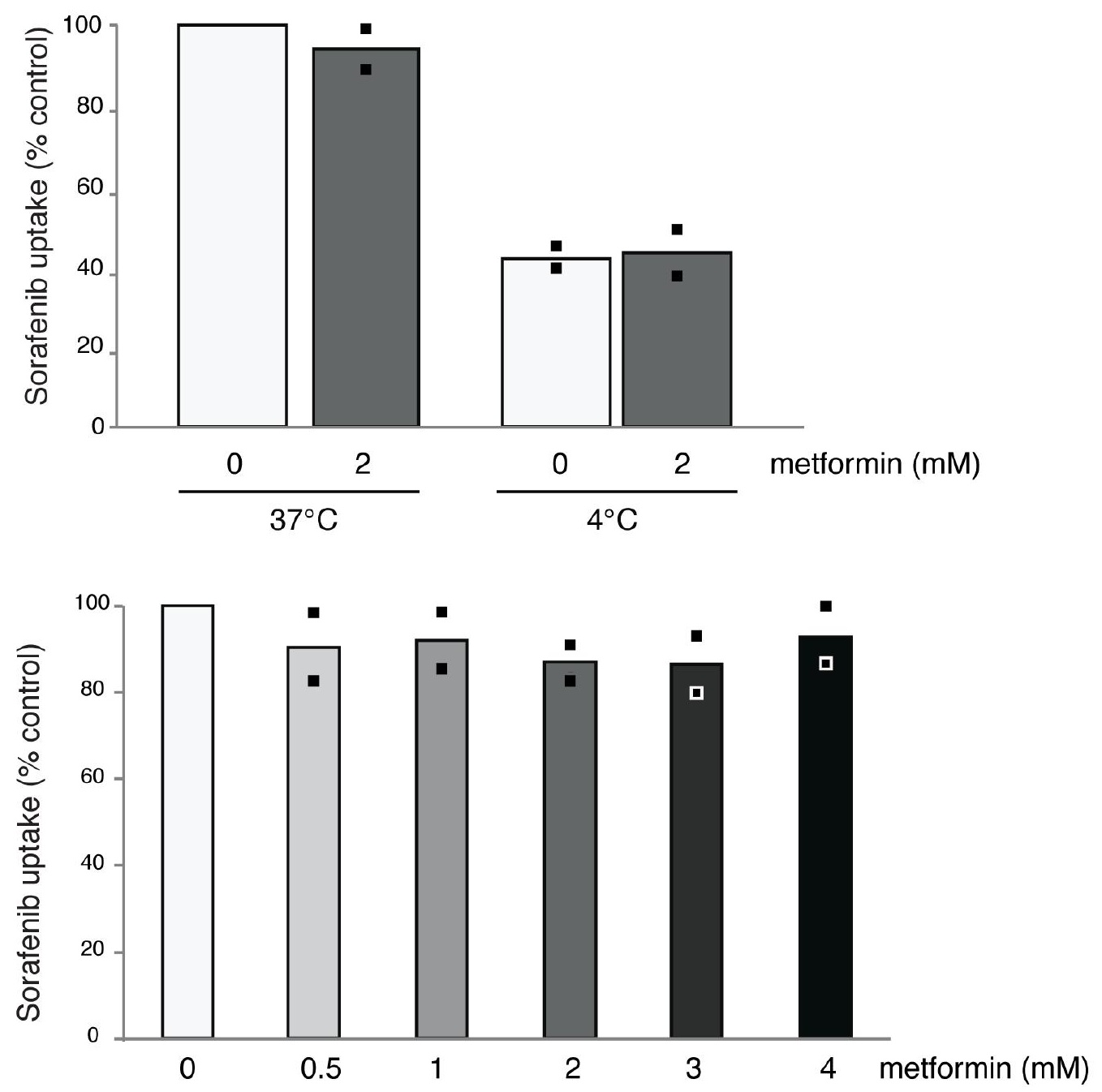
Figure 3

a
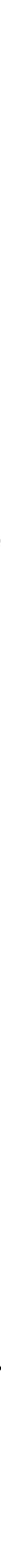
Figure 2

a
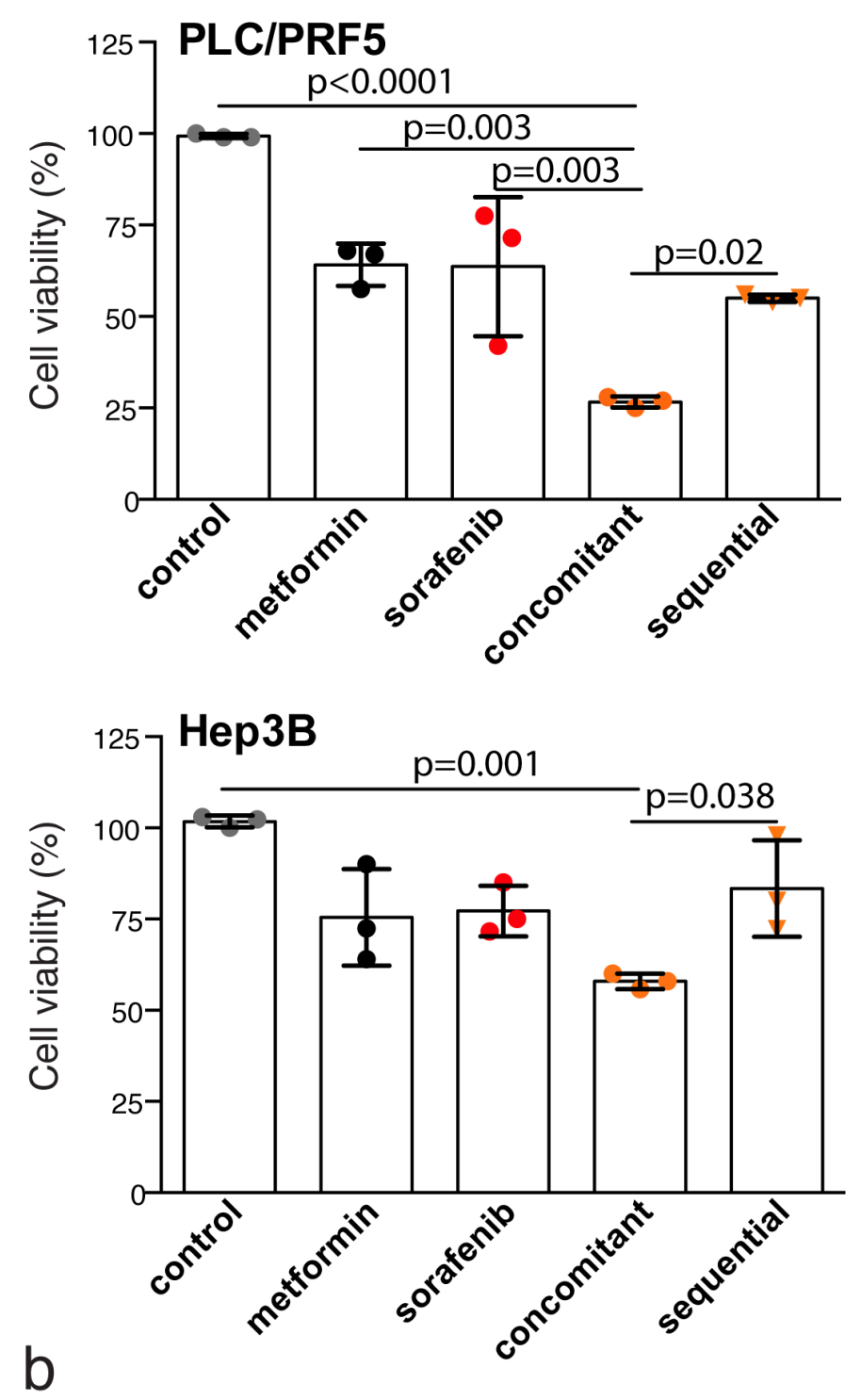

1007 PLC/PRF5

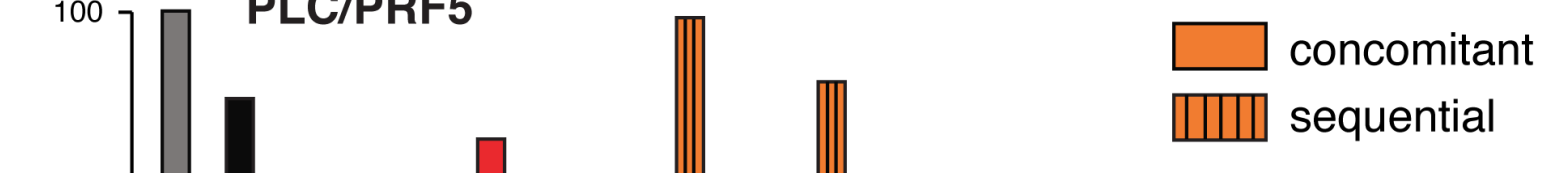

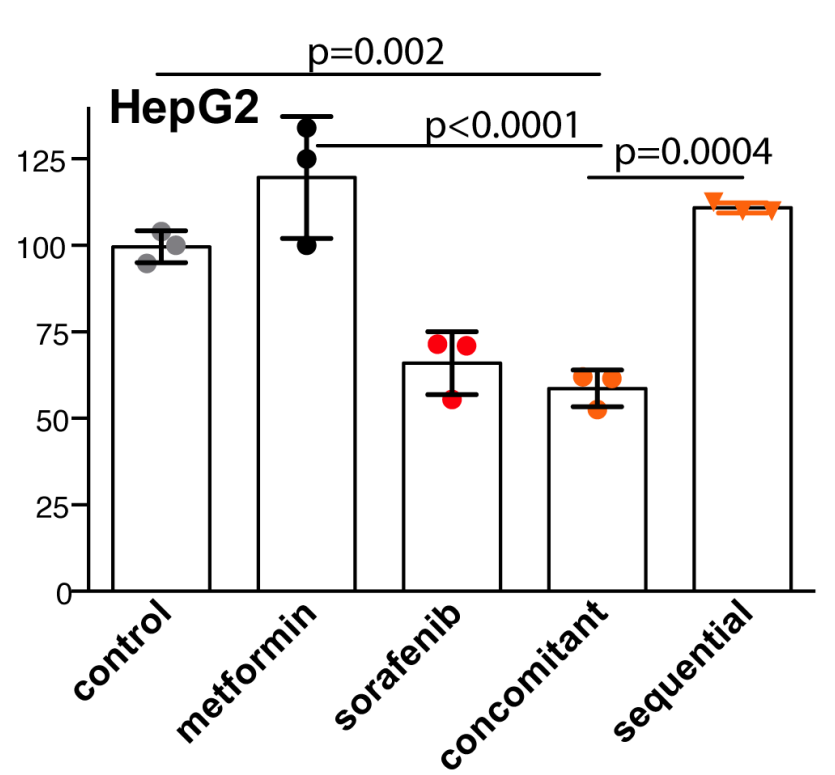

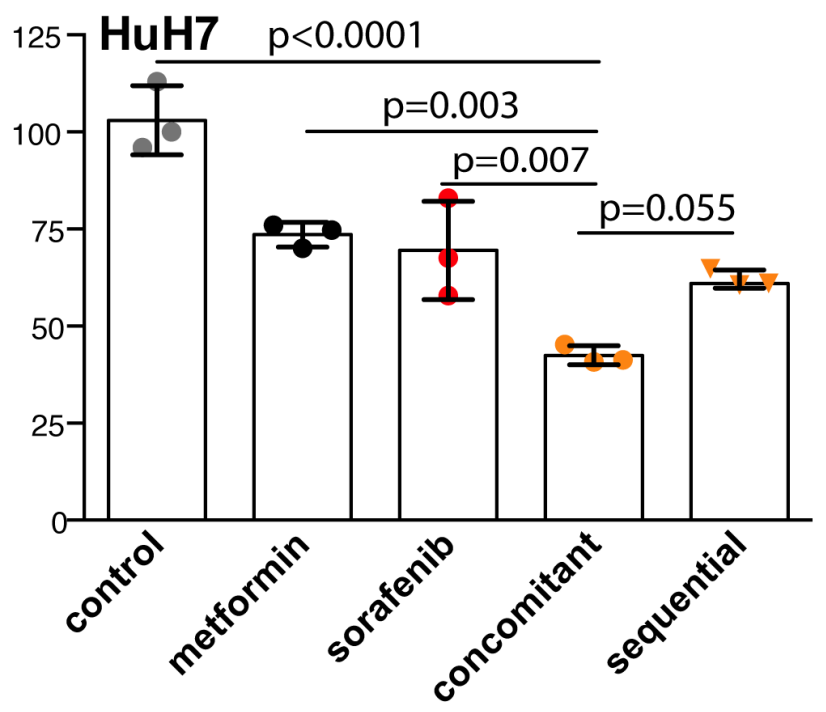


a

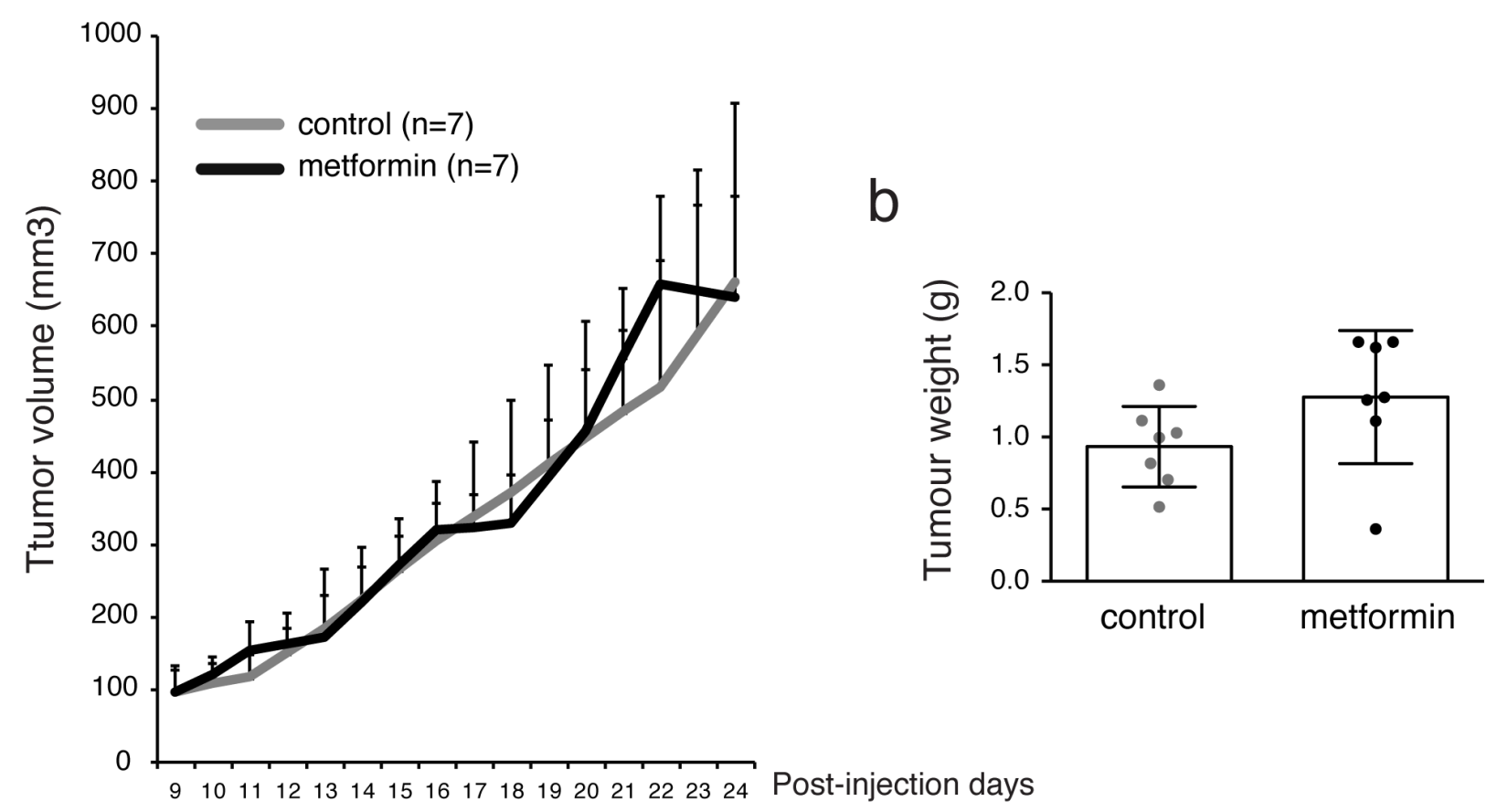

C
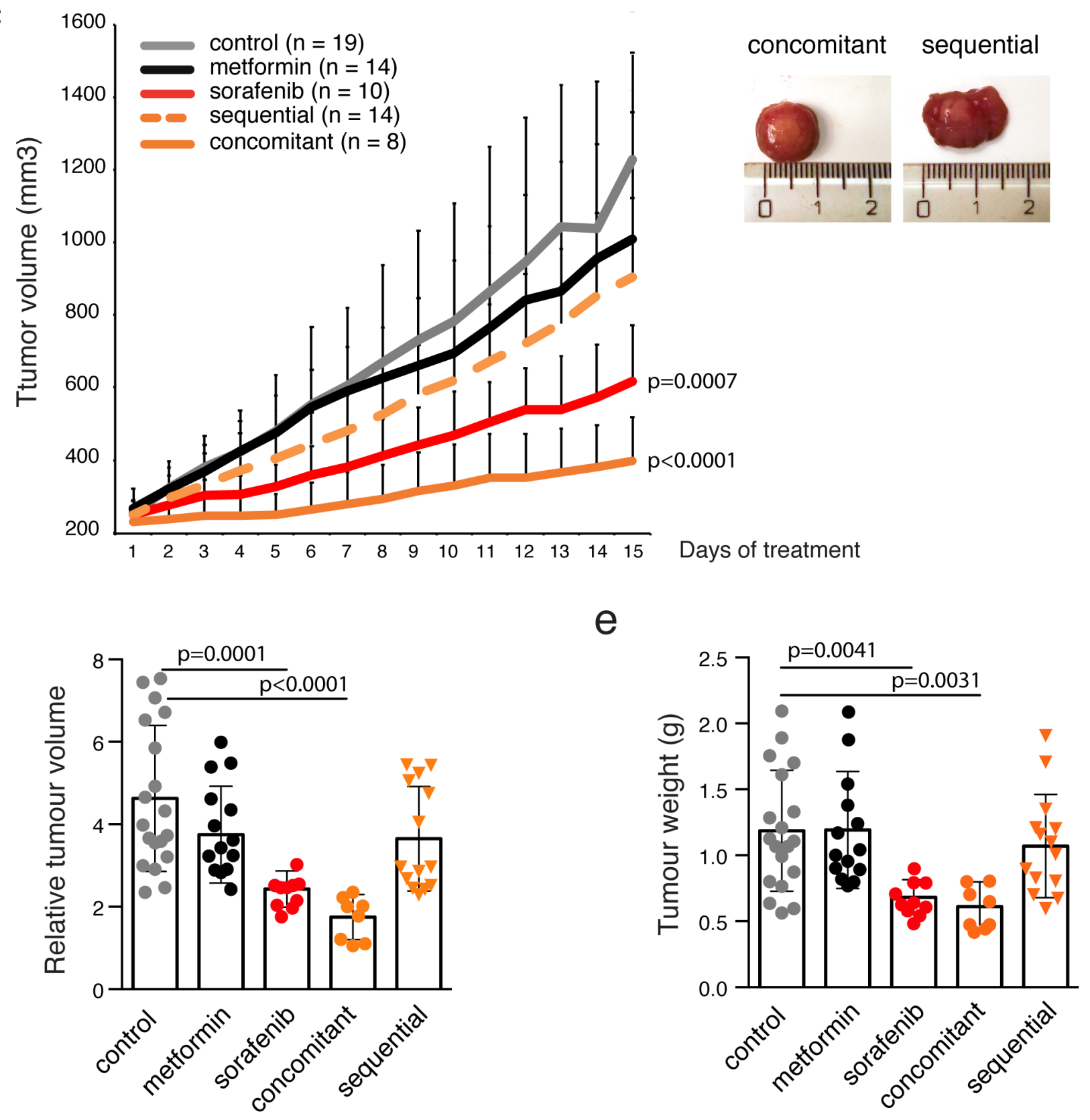
Visual abstract for manuscript \# MOLPHARM-AR-2020-000223

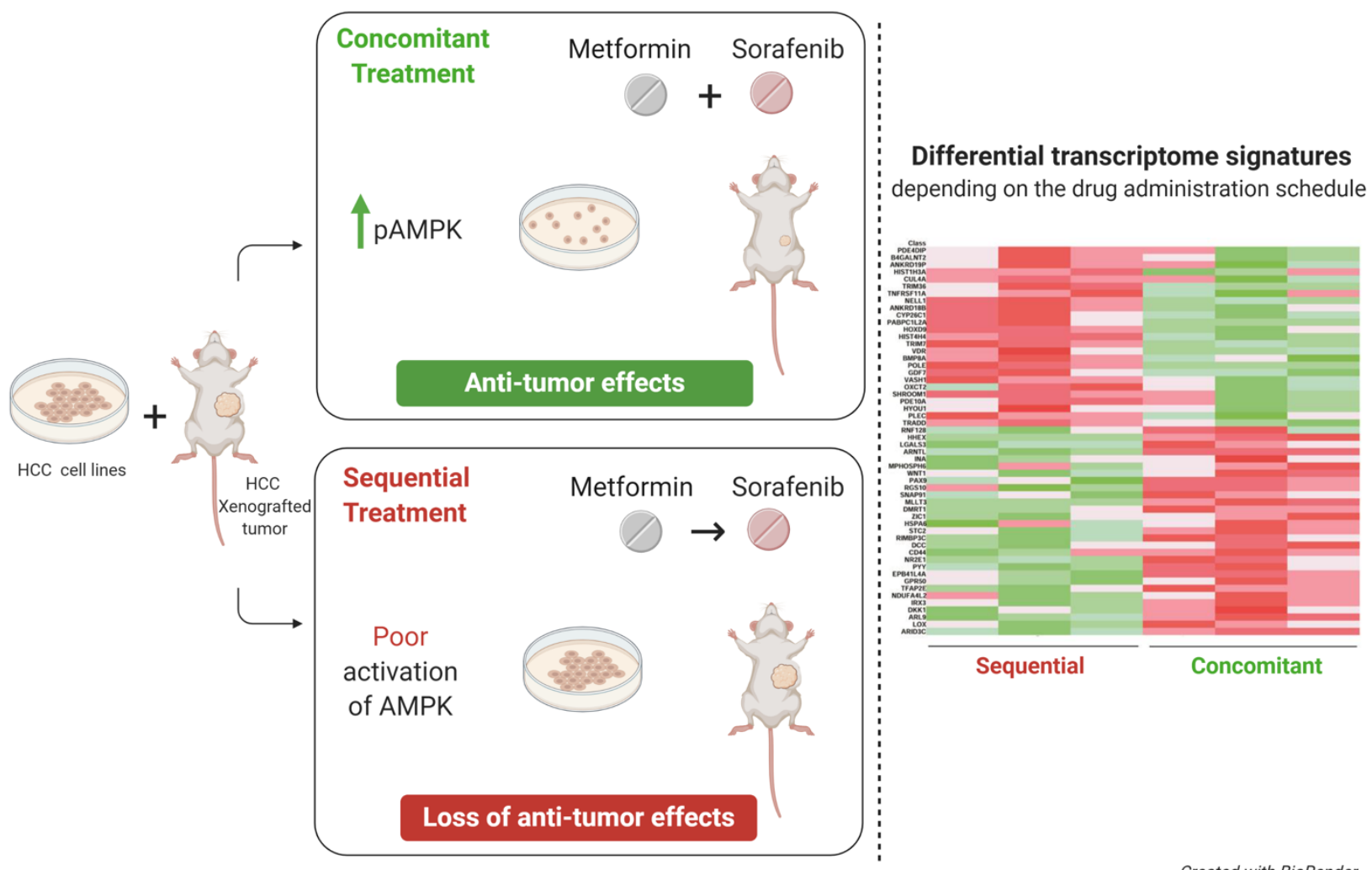


Supplemental data for manuscript \# MOLPHARM-AR-2020-000223

Drug-drug interaction between metformin and sorafenib alters antitumor effect in hepatocellular carcinoma cells

Rania Harati, Marc Vandamme, Benoit Blanchet, Christophe Bardin, Françoise Praz, Rifat Akram Hamoudi, Christèle Desbois-Mouthon 


\section{Supplemental figure S1}

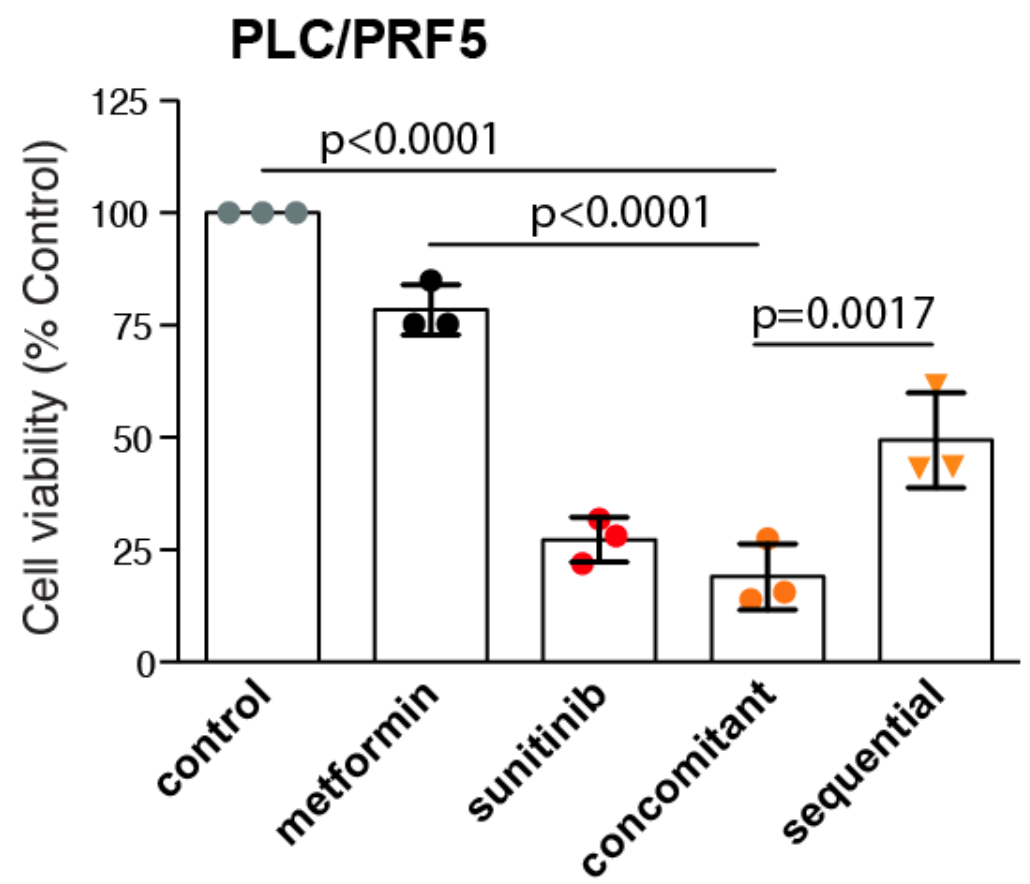

Figure S1. Effects of the concomitant and sequential combinations of metformin and sunitinib on cell viability in human PLC/PRF5 cell line

PLC/PRF5 cells were seeded in 24 -well plates $\left(3 \times 10^{5}\right.$ cells per well) and allowed to proliferate for $24 \mathrm{~h}$ in complete medium. Then cells were incubated for a further $72 \mathrm{~h}$ in the presence or not of metformin $(1 \mathrm{mM})$, sunitinib $(8 \mu \mathrm{M})$, metformin combined to sunitinib or metformin followed $6 \mathrm{~h}$ later by sunitinib. At the end of the treatment period, cell viability was measured using the MTT assay. Data are mean \pm SD of 3 independent experiments performed in 8 determinations. $P$ values were determined using one-way ANOVA relative to the concomitant condition. $P$ values for other multiple comparisons are presented in supplementary Table S1. 
Supplemental data for manuscript \# MOLPHARM-AR-2020-000223

Drug-drug interaction between metformin and sorafenib alters antitumor effect in hepatocellular carcinoma cells

Rania Harati, Marc Vandamme, Benoit Blanchet, Christophe Bardin, Françoise Praz, Rifat Akram Hamoudi, Christèle Desbois-Mouthon 
Table S1. Adjusted P values for multiple comparisons by one-way ANOVA.

\author{
Figure 2 Huh7 \\ Tukey's multiple comparisons test \\ control vs. metformin \\ control vs. sorafenib \\ control vs. concomitant \\ control vs. sequential \\ metformin vs. sorafenib \\ metformin vs. concomitant \\ metformin vs. sequential \\ sorafenib vs. concomitant \\ sorafenib vs. sequential \\ concomitant vs. sequential
}

Figure 2 HepG2

Tukey's multiple comparisons test
control vs. metformin
control vs. sorafenib
control vs. concomitant
control vs. sequential
metformin vs. sorafenib
metformin vs. concomitant
metformin vs. sequential
sorafenib vs. concomitant
sorafenib vs. sequential
concomitant vs. sequential

Figure 2 PLC/PRF5

Tukey's multiple comparisons test

control vs. metformin

control vs. sorafenib

control vs. concomitant

control vs. sequential

metformin vs. sorafenib

metformin vs. concomitant

metformin vs. sequential

sorafenib vs. concomitant

sorafenib vs. sequential

Mean Diff.
29.43
33.5
60.53
41.5
4.067
31.1
12.07
27.03
8
-19.03

$95 \% \mathrm{Cl}$ of diff.

9.981 to 48.89

14.05 to 52.95

41.08 to 79.99

22.05 to 60.95

-15.39 to 23.52

11.65 to 50.55

-7.385 to 31.52

7.581 to 46.49

-11.45 to 27.45

-38.49 to 0.4187

Mean Diff,
-20.07
33.6
40.93
-11.23
53.67
61
8.833
7.333
-44.83
-52.17

$95,00 \% \mathrm{Cl}$ of diff,

$-45,42$ to 5,285

8,249 to 58,95

15,58 to 66,28

$-36,58$ to 14,12

28,32 to 79,02

35,65 to 86,35

$-16,52$ to 34,18

$-18,02$ to 32,68

$-70,18$ to $-19,48$

$-77,52$ to $-26,82$

Mean Diff,
35.17
35.67
72.67
44.33
0.5
37.5
9.167
37
8.667

$95,00 \% \mathrm{Cl}$ of diff,

11,18 to 59,15

11,68 to 59,65

48,68 to 96,65

20,35 to 68,32

$-23,48$ to 24,48

13,52 to 61,48

$-14,82$ to 33,15

13,02 to 60,98

$-15,32$ to 32,65

Adjusted P Value
$\mathbf{0 . 0 0 3 9}$
$\mathbf{0 . 0 0 1 5}$
$<\mathbf{0 . 0 0 0 1}$
$\mathbf{0 . 0 0 0 3}$
0.9546
$\mathbf{0 . 0 0 2 6}$
0.3143
$\mathbf{0 . 0 0 7}$
0.6674
0.0558

Adjusted P Value

0.1426

0.0097

0.0024

0.6081

0.0003

$<0.0001$

0.7795

0.8701

0.0012

0.0004
Adjusted P Value

0.0049

0.0044

$<0.0001$

0.0009

$>0.9999$

0.0031

0.7205

0.0034

0.7574 


\section{Figure 2 Hep3B}

Tukey's multiple comparisons test

control vs. metformin

control vs. sorafenib

control vs. concomitant

control vs. sequential

metformin vs. sorafenib

metformin vs. concomitant

metformin vs. sequential

sorafenib vs. concomitant

sorafenib vs. sequential

concomitant vs. sequential

Figure 5 PLC/PRF5

Tukey's multiple comparisons test

control vs. AICAR

control vs. sorafenib

control vs. sequential

control vs. concomitant

AICAR vs. sorafenib

AICAR vs. sequential

AICAR vs. concomitant

sorafenib vs. sequential

sorafenib vs. concomitant

sequential vs. concomitant

Figure 5 Huh7

Tukey's multiple comparisons test

Control vs. AICAR

Control vs. sorafenib

Control vs. concomitant

Control vs. sequential

AICAR vs. sorafenib

AICAR vs. concomitant

AICAR vs. sequential

sorafenib vs. concomitant

sorafenib vs. sequential

concomitant vs. sequential
Mean Diff,

26.3

24.57

43.83

18.36

$-1.733$

17.53

$-7.943$

19.27

$-6.21$

$-25.48$

Mean Diff,

13.56

44.16

51.88

66.46

30.6

38.31

52.9

7.717

22.3

14.58

\section{Mean Diff.}

13.73

30.24

60.12

28.18

16.51

46.38

14.45

29.87

$-2.063$

$-31.94$
$95,00 \% \mathrm{Cl}$ of diff,

2,080 to 50,52

0,3466 to 48,79

19,61 to 68,05

$-5,863$ to 42,58

$-25,95$ to 22,49

$-6,687$ to 41,75

$-32,16$ to 16,28

$-4,953$ to 43,49

$-30,43$ to 18,01

$-49,70$ to $-1,257$

$95,00 \% \mathrm{Cl}$ of diff,

2,439 to 24,69

33,04 to 55,28

40,75 to 63,00

55,34 to 77,59

19,47 to 41,72

27,19 to 49,44

41,77 to 64,02

$-3,408$ to 18,84

11,18 to 33,43

3,459 to 25,71
Adjusted P Value

0.0322

0.0465

0.001

0.1678

0.9992

0.1972

0.813

0.1399

0.9106

0.0384

\section{Adjusted P Value}

0.0164

$<0.0001$

$<0.0001$

$<0.0001$

$<0.0001$

$<0.0001$

$<0.0001$

0.2269

0.0005

0.0104
$95 \% \mathrm{Cl}$ of diff.

1.221 to 26.25

17.73 to 42.76

47.60 to 72.63

15.67 to 40.69

3.998 to 29.02

33.87 to 58.90

1.935 to 26.96

17.36 to 42.39

-14.58 to 10.45

-44.45 to -19.42
Adjusted P Value

0.0304

$<0.0001$

$<0.0001$

0.0002

0.0099

$<0.0001$

0.0227

0.0001

0.9804

$<0.0001$ 


\section{Supplemental Figure 1}

\section{Tukey's multiple comparisons test}

control vs. metformin

control vs. sunitinib

control vs. concomitant

control vs. sequential

metformin vs. sunitinib

metformin vs. concomitant

metformin vs. sequential

sunitinib vs. concomitant

sunitinib vs. sequential

concomitant vs. sequential
Mean Diff,

21.54

72.73

81.02

50.62

51.19

59.48

29.09

8.29

$-22.11$

$-30.4$
95,00\% $\mathrm{Cl}$ of diff,

3,626 to 39,45

54,82 to 90,64

63,11 to 98,93

32,71 to 68,53

33,28 to 69,10

41,57 to 77,39

11,18 to 47,00

$-9,621$ to 26,20

$-40,02$ to $-4,196$

$-48,31$ to $-12,49$
Adjusted P Value

0.0178

$<0.0001$

$<0.0001$

$<0.0001$

$<0.0001$

$<0.0001$

0.0023

0.5715

0.0152

0.0017 
Table S2. Cellular pathways differentially expressed between control and concomitant treatments.

\begin{tabular}{|c|c|c|c|c|c|c|}
\hline \multicolumn{7}{|c|}{ CONTROL versus CONCOMITANT TREATMENT } \\
\hline \multicolumn{7}{|l|}{ c2 } \\
\hline GS & SIZE & ES & NES & Tag \% & Gene \% & Signal \\
\hline REACTOME_G_ALPHA_S_SIGNALLING_EVENTS & 21 & 0.53248 & 1.5112 & 0.952 & 0.448 & 0.536 \\
\hline REACTOME_OLFACTORY_SIGNALING_PATHWAY & 16 & 0.56035 & 1.5103 & 1 & 0.448 & 0.56 \\
\hline KEGG_OLFACTORY_TRANSDUCTION & 16 & 0.56035 & 1.4098 & 1 & 0.448 & 0.56 \\
\hline RAY_TUMORIGENESIS_BY_ERBB2_CDC25A_UP & 15 & 0.52866 & 1.3987 & 0.667 & 0.271 & 0.493 \\
\hline REACTOME_PHOSPHOLIPID_METABOLISM & 16 & 0.45114 & 1.3445 & 0.375 & 0.17 & 0.316 \\
\hline OSMAN_BLADDER_CANCER_DN & 15 & 0.33939 & 1.2361 & 0.267 & 0.129 & 0.236 \\
\hline \multicolumn{7}{|l|}{ c5 } \\
\hline GO_SENSORY_PERCEPTION_OF_SMELL & 18 & 0.56146 & 1.8089 & 1 & 0.448 & 0.561 \\
\hline GO_SENSORY_PERCEPTION_OF_CHEMICAL_STIMULUS & 22 & 0.55972 & 1.805 & 1 & 0.452 & 0.56 \\
\hline GO_DETECTION_OF_STIMULUS_INVOLVED_IN_SENSORY_PERCEPTION & 22 & 0.55972 & 1.7687 & 1 & 0.452 & 0.56 \\
\hline GO_OLFACTORY_RECEPTOR_ACTIVITY & 17 & 0.5609 & 1.6738 & 1 & 0.448 & 0.561 \\
\hline GO_MONOCARBOXYLIC_ACID_METABOLIC_PROCESS & 18 & 0.56383 & 1.5643 & 0.5 & 0.17 & 0.422 \\
\hline GO_DETECTION_OF_STIMULUS & 30 & 0.50227 & 1.562 & 0.9 & 0.452 & 0.508 \\
\hline GO_LIPID_LOCALIZATION & 16 & 0.70441 & 1.5321 & 0.625 & 0.136 & 0.548 \\
\hline GO_SENSORY_PERCEPTION & 38 & 0.46803 & 1.513 & 0.842 & 0.452 & 0.479 \\
\hline GO_G_PROTEIN_COUPLED_RECEPTOR_ACTIVITY & 43 & 0.43941 & 1.4741 & 0.791 & 0.448 & 0.455 \\
\hline GO_CYTOKINE_PRODUCTION & 33 & 0.45672 & 1.455 & 0.424 & 0.168 & 0.365 \\
\hline GO_ORGANIC_ACID_METABOLIC_PROCESS & 29 & 0.43233 & 1.4548 & 0.379 & 0.19 & 0.316 \\
\hline GO_TRANSMEMBRANE_SIGNALING_RECEPTOR_ACTIVITY & 61 & 0.42633 & 1.4396 & 0.738 & 0.432 & 0.445 \\
\hline GO_MOLECULAR_TRANSDUCER_ACTIVITY & 73 & 0.39116 & 1.4271 & 0.685 & 0.432 & 0.419 \\
\hline GO_ORGANONITROGEN_COMPOUND_CATABOLIC_PROCESS & 50 & 0.32198 & 1.3997 & 0.28 & 0.19 & 0.238 \\
\hline GO_LIPID_METABOLIC_PROCESS & 61 & 0.33109 & 1.3704 & 0.295 & 0.17 & 0.26 \\
\hline GO_MUSCLE_CONTRACTION & 15 & 0.52138 & 1.3456 & 0.8 & 0.389 & 0.496 \\
\hline GO_REGULATION_OF_ION_TRANSPORT & 31 & 0.35411 & 1.3031 & 0.613 & 0.421 & 0.366 \\
\hline GO_NERVOUS_SYSTEM_PROCESS & 57 & 0.3831 & 1.2556 & 0.719 & 0.465 & 0.407 \\
\hline GO_POSITIVE_REGULATION_OF_CELL_ADHESION & 22 & 0.46725 & 1.2534 & 0.773 & 0.409 & 0.467 \\
\hline GO_REGULATION_OF_CELL_ADHESION & 38 & 0.41378 & 1.2423 & 0.658 & 0.409 & 0.404 \\
\hline GO_IMMUNE_SYSTEM_DEVELOPMENT & 40 & 0.30727 & 1.1881 & 0.475 & 0.353 & 0.32 \\
\hline GO_PROTEIN_FOLDING & 17 & -0.43912 & -1.5192 & 0.882 & 0.312 & 0.617 \\
\hline GO_REGULATION_OF_PROTEIN_STABILITY & 17 & -0.37789 & -1.5042 & 0.765 & 0.257 & 0.578 \\
\hline GO_TRANSFERASE_COMPLEX & 37 & -0.23815 & -1.235 & 0.838 & 0.504 & 0.431 \\
\hline
\end{tabular}


Table S3. Cellular pathways differentially expressed between control and sequential treatments.

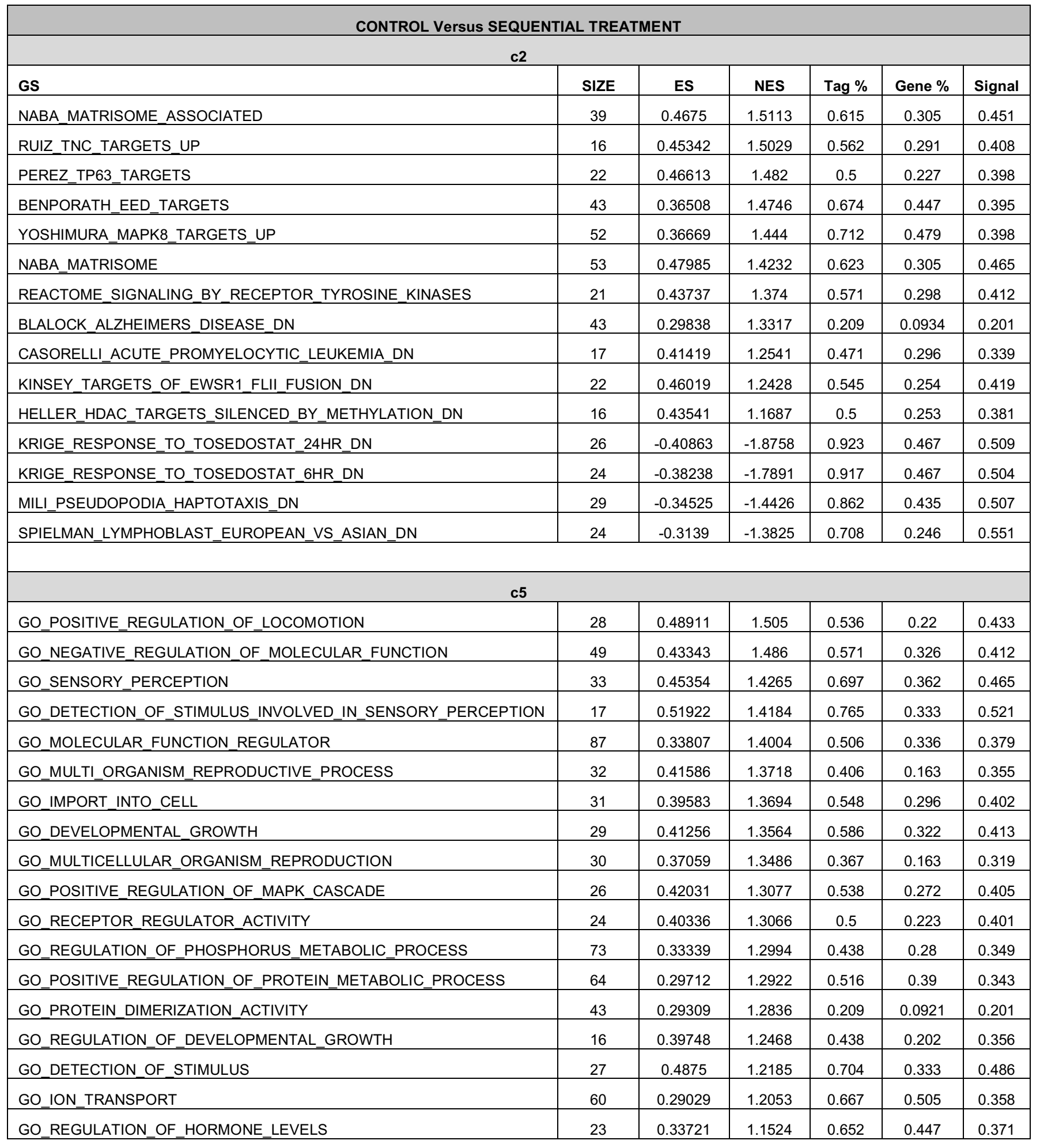


Table S4. Cellular pathways differentially expressed between sequential and concomitant treatments.

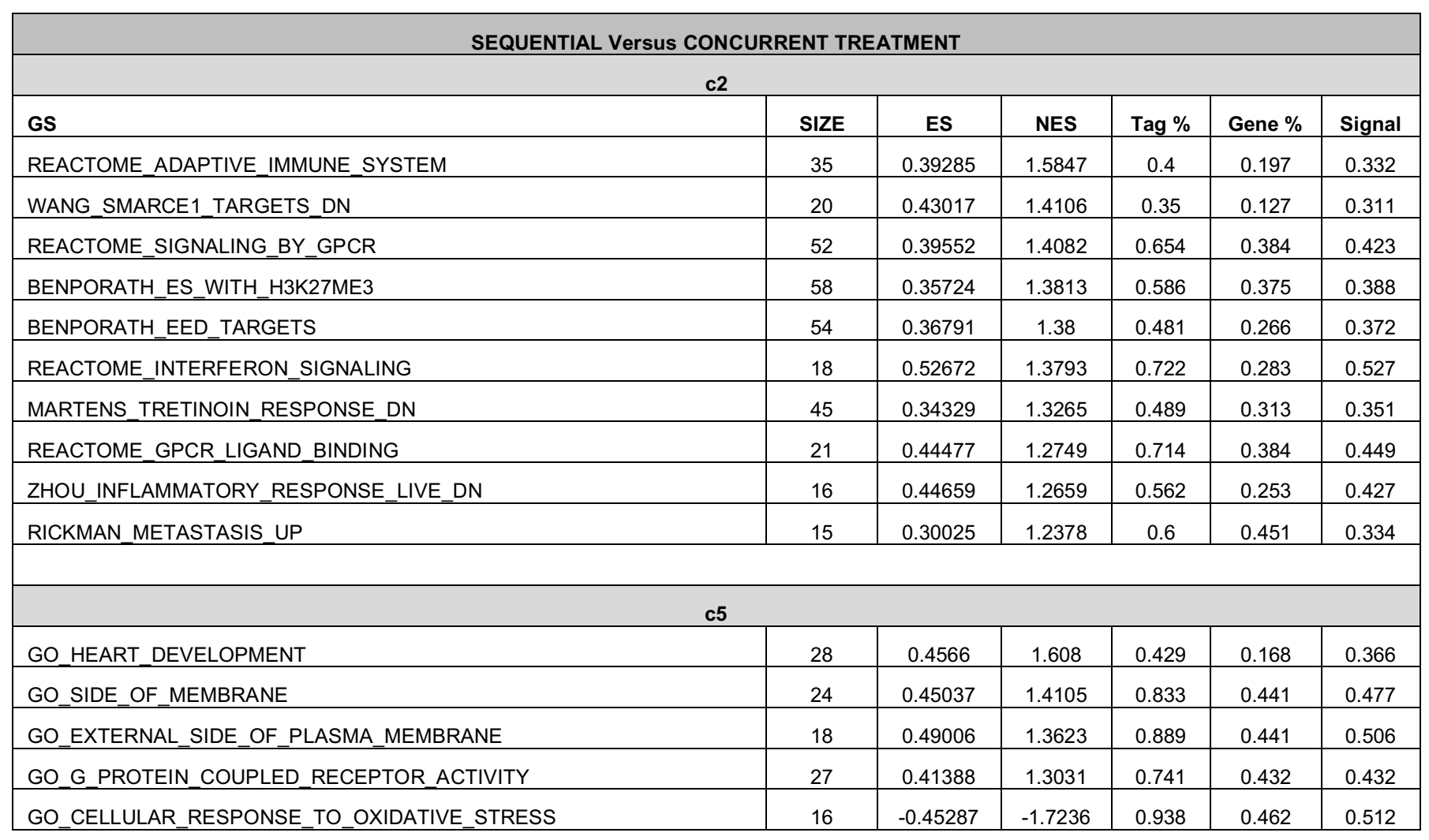

